NBER WORKING PAPER SERIES

\title{
COMPETITIVE EFFECTS OF SCOPE OF PRACTICE RESTRICTIONS: PUBLIC HEALTH OR PUBLIC HARM?
}

\author{
Sara Markowitz \\ E. Kathleen Adams \\ Mary Jane Lewitt, PhD,CNM \\ Anne Dunlop, MD \\ Working Paper 22780 \\ http://www.nber.org/papers/w22780 \\ NATIONAL BUREAU OF ECONOMIC RESEARCH \\ 1050 Massachusetts Avenue \\ Cambridge, MA 02138 \\ October 2016
}

Funding for this research was provided by AHRQ grant 1R01HS024530. We thank Megan Kelly for her work on coding the laws, and Jonathan Hawley and Peter Joski for excellent research assistance. We also thank Christine Durrance and seminar participants at Clemson University, University of Alabama at Birmingham, the APPAM annual meeting and the ASHEcon biennial meeting for extremely helpful comments. The views expressed herein are those of the authors and do not necessarily reflect the views of the National Bureau of Economic Research.

NBER working papers are circulated for discussion and comment purposes. They have not been peer-reviewed or been subject to the review by the NBER Board of Directors that accompanies official NBER publications.

(C) 2016 by Sara Markowitz, E. Kathleen Adams, Mary Jane Lewitt, PhD,CNM, and Anne Dunlop, MD. All rights reserved. Short sections of text, not to exceed two paragraphs, may be quoted without explicit permission provided that full credit, including $(\odot)$ notice, is given to the source. 
Competitive Effects of Scope of Practice Restrictions: Public Health or Public Harm?

Sara Markowitz, E. Kathleen Adams, Mary Jane Lewitt, PhD,CNM, and Anne Dunlop, MD

NBER Working Paper No. 22780

October 2016

JEL No. I1,J44,K2

\begin{abstract}
The demand for health care and healthcare professionals is predicted to grow significantly over the next decade. Securing an adequate health care workforce is of primary importance to ensure the health and wellbeing of the population in an efficient manner. Occupational licensing laws and related restrictions on scope of practice (SOP) are features of the market for healthcare professionals and are also controversial. At issue is a balance between protecting the public health and removing anticompetitive barriers to entry and practice. In this paper, we examine the controversy surrounding SOP restrictions for certified nurse midwives (CNMs). We use the variation in SOP laws governing CNM practice that has occurred over time in a quasiexperimental design to evaluate the effect of the laws on the markets for CNMs and their services, and on related maternal and infant outcomes. We focus on SOP laws that pertain to physician oversight requirements and prescribing rules, and examine the effects of SOP laws in geographic areas designated as medically underserved. Our findings indicate that SOP laws are neither helpful nor harmful in regards to maternal behaviors and infant health outcomes, but states that allow CNMs to practice with no SOP-based barriers to care have lower rates of induced labor and Cesarean section births. We discuss the implications of these findings for the policy debate surrounding SOP restrictions and for health care costs.
\end{abstract}

Sara Markowitz

Department of Economics

Emory University

1602 Fishburne Dr.

Atlanta, GA 30322

and NBER

sara.markowitz@emory.edu

E. Kathleen Adams

Emory School of Public Health

1518 Clifton Road, NE

Atlanta, GA 30322

eadam01@emory.edu
Mary Jane Lewitt, PhD,CNM

Nell Hodgson Woodruff School of Nursing

Emory University

1520 Clifton Rd

Atlanta, GA 30322

mlewitt@emory.edu

Anne Dunlop, MD

Nell Hodgson Woodruff School of Nursing

Emory University

1520 Clifton Rd

Atlanta, GA 30322

amlang@emory.edu 


\section{Introduction}

As a result of population growth, the aging of the population, and continued implementation of the Affordable Care Act (ACA), the demand for health care and healthcare professionals is predicted to grow tremendously over the next decade. The Bureau of Labor Statistics (BLS) estimates that the collective healthcare occupation will be one of the fastest growing, far outpacing the growth in other industries and adding 2.3 million new jobs by 2024 (BLS 2015). At the same time, others predict that demand for workers will outpace supply, leading to a shortage of 35,000-52,000 adult primary care physicians by 2025 (Petterson et al. 2012). In the face of this changing landscape, securing an adequate health care workforce is of primary importance to ensure the health and wellbeing of the population, as well as meeting national goals of improving the efficiency of the healthcare system (Heisler 2013).

The trajectory of the healthcare workforce is shaped by a variety of factors, with one of the most important being issues related to occupational licensing. The Bureau of Labor Statistics estimates that $72.2 \%$ of healthcare practitioners (6.33 million workers) are licensed and subject to laws regulating those licenses (BLS 2016). Healthcare practitioners are licensed by the states in which they practice, earning their license by completing the required years of education and practical training, and passing national exams. In general, occupational licenses exist to ensure that practitioners are knowledgeable and competent, and therefore protect the public from potential harm (Bryson and Kleiner 2010). However, certain provisions of licenses can also generate significant barriers to workforce entry, restrict competition, raise prices, and protect guilds.

Beyond the initial licensing requirements guiding entry into the profession, many health care practitioners, generally non-physicians, face additional "scope of practice" license 
restrictions after entry. These scope of practice (SOP) laws are set by the states and define the range of tasks legally allowed for a given provider, within state boundaries. Physicians generally have no restrictions on their SOP, are free to practice medicine as they see fit, and perhaps earn economic rents. Other practitioners, including physician assistants, advanced practice registered nurses (APRNs), dental hygienists, and optometrists, often face restrictions on their SOP. It is these restrictions that have become a source of controversy in recent years as it is argued that they may generate unnecessary barriers to practice, block patients' access to care and restrict the achievement of efficiencies in the overall health care system. Lifting restrictions is seen as one solution to primary care shortages that can also result in improved access to care and cost savings. Indeed, the current movement among states is to lift SOP restrictions and move towards "fully enabled" SOP for many types of health practitioners.

The controversy surrounding SOP regulation of healthcare practitioners is particularly acute in the market for APRNs. Critics contend that quality of care may suffer under an APRN's direction, citing the shorter length of training and clinical experience required. Proponents argue that APRNs improve efficiency of the system by providing care that is similar in quality to that of physicians while reducing costs substantially (AAFP 2012, Schiff 2012). The heart of the controversy lies in the determination of the costs and benefits. What remains unknown is whether SOP restrictions complement licensing requirements in a way that protects the public from potential harm, or if these restrictions simply generate artificial barriers and protect physician rents. This line of inquiry is important for a subset of APRNs, Certified Nurse Midwives (CNMs) whose education allows them to manage women's health during pregnancy, birth, and the postpartum period. The costs of births at delivery equaled about $\$ 39$ billion in 2013 (based on authors' calculations of the Medical Expenditure Panel Survey (MEPS)), with almost 
half of that paid by taxpayers through the Medicaid program; the largest driver of the costs of delivery is whether it is vaginal or by $\mathrm{C}$-section.

In this paper, we examine this controversy and evaluate the effects of varying levels of SOP restrictions on health outcomes relevant to the CNM practice. CNMs are APRNs whose practice is defined as the independent management of women's health care. It focuses on pregnancy, childbirth, postpartum care, newborn care, and the family planning and gynecological needs of women. We use the natural experiment of states' changes in laws affecting the SOP for CNMs over the 1994-2013 time period to evaluate the effect of the laws on the markets for CNMs and their services, and on related maternal and infant outcomes. We focus on SOP laws that pertain to physician oversight requirements and prescribing rules, and examine the effects of SOP laws in geographic areas designated as medically underserved. We estimate a reduced form equation that links the laws directly to health outcomes and to the intermediary mechanisms of CNM employment levels and consumers' choice of provider.

The results of this study inform the debate surrounding the movement to fully enabled SOP for APRNs in general, but specifically, as it pertains to CNMs. We show that states that allow for CNMs fully enabled practice, have on average, little or no differences in maternal health behaviors or infant health outcomes as compared to states with more restrictive SOP. There are however, noticeable differences in rates of labor inductions, elective labor inductions, $\mathrm{C}$-sections and elective C-sections, with fully enabled SOP states having lower probabilities of these procedures. The results point to the conclusion that restrictions on CNM SOP primarily serve as barriers to practice and removing these restrictions has the potential to improve the efficiency of the health care system for delivery and infant care. 


\section{Background}

Scope of practice laws are the legal authority given to health care providers to provide medical services. For nurses, these laws specifically “define nurses' roles, articulate oversight requirements, and govern practice and prescriptive authorities." (Naylor and Kurtzman 2010, p. 896). The two most common and broad reaching of these laws pertaining to practice oversight requirements and prescription authority. The SOP laws pertaining to practice authority specify the degree of practice independence, which range from no specific requirements to collaborative or consultative arrangements with physicians, to supervisory relationships. SOP laws regarding prescription authority dictate whether or not an APRN can write prescriptions, and if so, for which types of drugs, and whether physician involvement is required.

The current regulatory environments for APRNs (including CNMs) vary tremendously by state and range from restrictive supervisory relationships to complete independence. Restrictive practice laws generate barriers to practice by requiring additional documentation (e.g., cosignatures on charts and orders), delays in care for patients receiving treatments and medications (such as those that occur when physicians must be contacted to order medications or treatments), and disruptions of care continuity (when medical results or consultation reports are sent to the physician of record and not the actual care provider).

The relevant public policy question surrounding these laws is whether states should allow APRNs to practice to the full extent of their training with no physician oversight. Full practice authority is recommended for these practitioners by groups like the Institute of Medicine (IOM), Robert Wood Johnson Foundation (RWJF), and National Governors Association (NGA) based on conclusions from academic research comparing health care quality among the different providers. The most common comparison in these studies is that of nurse practitioners (NPs), 
who provide primary care services, to physicians. Newhouse et al. (2011) and the National Governers Association (Schiff 2012) provide comprehensive reviews of this literature and conclude that the quality of care provided by NPs is similar to that of physicians. The quality measures include patient satisfaction, time spent with patients, prescription accuracy, and changes in physiological measures. The Newhouse et al. study also compared CNM to physician care and found CNM groups show lower rates of episiotomy, cesarean sections, epidural use, perineal lacerations, and neonatal intensive care unit admission. They also show comparable rates of APGAR score, labor augmentation, labor induction, low birth weight, vaginal operative delivery, and vaginal birth after caesarian section (Newhouse et al. 2011).

The consensus of this literature finding comparable or superior outcomes for the APRNs is compelling but almost all of the outcome-based comparisons were conducted without regard to the scope of practice environment in which the study is undertaken. Thus, the existing quality comparisons do not inform the debate surrounding the movement by a state from restrictive to fully enabled SOP. Consider for example, the list of U.S.-based studies shown in Table 1 below, drawn from a review article by Johantgen et al. (2012) that is often cited as evidence supporting the use of CNMs. We list the "high quality" studies identified by Johantgen et al. for which we could identify the geographic area and the practice environment under which the data were collected. We show that the practice environments differ by state but are dominated by restrictive SOP laws. While the article draws the conclusion that "the findings provide evidence that care by CNMs is safe and effective", given the different practice environments under which the studies are conducted, a more accurate conclusion is that CNM care is safe and effective under several types of practice environments, including physician oversight. The literature leaves the 
main question unanswered. It does not provide information as to whether changing the SOP laws protect the public's health and this is the gap in the literature we fill.

There exists a modest academic literature on the effects of occupational licensing (for example, Gittleman et al. 2015; Kleiner and Kruger 2013, Kleiner and Kruger 2010), but very little research has specifically evaluated the effects of the scope of practice restrictions that cover millions of health care workers. The existing literature primarily focuses on labor market effects (changes in employment levels, hours, or earnings) and product market effects (changes in prices, utilization, or expenditures) arising from changes in the SOP laws. Provider types studied include nurse practitioners (Kleiner et al. 2016; Timmons 2016; Stange 2014; Spetz et al. 2013; Perry 2009), physician assistants (Timmons 2016; Stange 2014; Perry 2009), dental hygienists (Kleiner and Park 2010; Wing and Marier 2014); and chiropractors (Timmons et al. 2014). Within this literature for nurse practitioners, independent SOP for prescription drugs are found to have no effects on infant mortality rates (Kleiner et al. 2016) nor self-reported health status (Stange 2014).

Two studies examine the health effects of restrictive SOP specifically for CNMs. One older study, Declercq et al. (1998), is a correlational study using two years of data from the 1990s. The authors find evidence that high legislative support for CNM practice is associated with more CNMs and CNM attended births, lower rates of infant mortality, and lower rates of low birth weight. A more recent study by Yang et al. (2016) uses a recent cross-section of states to conduct a correlational study between the autonomy of CNM and birth outcomes. The authors find that autonomous CNM practice is associated with lower probabilities of labor induction, cesarean delivery, preterm birth and low birth weight. Although the authors control for demographic characteristics of the mother, the law's effects are identified only off of cross-state 
variation. Their estimates are therefore highly likely to be biased because of the presence of unmeasured characteristics of states and patient populations that are correlated with practice environments.

Two other relevant studies that examine outcomes related to midwifery include Miller (2006) and Anderson et al. (2016). Miller examines insurance reimbursement mandates for CNMs and finds these mandates increase the share of births attended by CNMs, but have no effect on C-section rates, Apgar scores, birth weight or maternal mortality. The analysis does, however, find reductions in neonatal and infant mortality. Anderson et al. (2016) take a historical perspective and examines the effects of state midwifery licensing laws introduced between 1900 and 1940. The find that licensing requirements are associated with reductions in maternal mortality and nonwhite infant mortality.

We advance the literature by presenting a comprehensive analysis of the range of SOP practice laws for CNMs on health outcomes and identify the effects using the changes in states' laws over a twenty year time period. We examine parts of the pathway of effects, including the effects on CNM employment, patients' use of CNMs, maternal prenatal behaviors, characteristics of labor and delivery, and infant health outcomes. In doing so, we seek to inform the debate surrounding the move to full practice authority for CNMs and to learn whether outcomes in states that allow them to practice independently and to the full extent of their training differ from states with more restrictive SOP laws. We also consider the effects of our findings on potential short-term cost savings pertaining to labor and delivery to be found within the health care system. 


\section{SOP Laws for CNMs}

The degree of physician involvement in the CNM practice as mandated by law varies widely across states and over time. Moreover, there are multiple ways to classify the laws. They can be broadly categorized into "restrictive", "collaborative" and "independent" practices. In "restrictive" practices, the CNM must be supervised or directed by a physician. In "collaborative" practices, states require a collaborative agreement with a physician in order to provide patient care. In "independent" practices there are no requirements for physician oversight, and the CNM is completely independent in practice and prescription authorities. All of these practice types may pertain to practice authority, prescription authority or both.

Within the broad categories just described, there are statutory details that reveal a range of practice allowance. For example, under collaborative SOP, some states require the CNM to practice under a written collaborative practice agreement (CPA), while others do not. A CPA is a document that outlines the working relationship between a physician and nurse. It may describe details of the practice including appropriate levels of consultation and referral, and reviews of diagnostic procedures, therapies, lab tests, and patient outcomes. These CPAs put in place some barriers to practice, including at a minimum, finding a physician with which to enter into a CPA and any monetary fees associated with setting up and maintaining the agreement. Furthermore, some of these CPAs are mandated to include written protocols that specifically dictate the practice protocol for case management of specific conditions or diagnoses. That is, these protocols state the specific procedures, tests, treatments and prescriptions the CNM can provide within the CPA. These protocols add further barriers to care over the CPA by limiting what the CNM can do independently. For example, a CPA with protocols may dictate a particular regimen of prescription medication for an infection, but if the patient has an allergy or 
intolerance to that medication, the $\mathrm{CNM}$ would be required to take time to contact a physician to modify the care for that particular patient.

CNM practice may be further restricted by supervisory-type of arrangements including delegation and direct supervision. However, even within these categories there is variation as to whether the state requires written protocols and whether supervision requirements (such as having the physician on-site or available by phone) are explicitly specified. For our analysis, we are interested in describing and grouping the laws based on the barriers to providing care, and therefore, generate and utilize the following classifications:

No barriers: In this classification, CNMs practice to the full extent of their training with no barriers to providing care. State laws include those with no oversight requirements at all and states that specify collaborative relationships but do not require a formal collaborative practice agreement nor written protocols.

Low barriers: State laws include those that specify collaborative practice agreements but do not require written protocols. Also included are states that are use the term "supervisory" relationship but do not require written protocols nor have any specific supervision requirements. CNMs in these states practice in collaborative arrangements with few barriers to care.

Moderate barriers: These state laws specifically require a written protocol describing allowable practices. The arrangement may be collaborative, delegative, or supervisory in nature, but all tend towards the same barriers to care through the written protocol.

High barriers: These states mandate that the CNM practice under the direct supervision of a physician, with supervision requirements specified. In some cases, the CNM has no authority to write prescriptions, but may be allowed to order prescriptions under the physician's name. 
It is important to note that over time, the trend in the laws has generally moved from the more restrictive supervisory relationships towards fully enabled practice with few or no restrictions. Also, as stated above, the legal relationships with physicians may pertain to the CNM's practice authority, prescription authority or both, and often differ within the same state. For example, there are some cases where the state statute allows for a CNM to practice independently in practice authority but under protocols if she wants to prescribe medications. Since we want to best describe the barriers to providing care, we combine the practice and prescription authorities, and classify the state by the more restrictive of the two.

We have used the information in The Nurse Practitioner's legislative update along with information gathered directly from each state's statutes pertaining specifically to CNMs to generate variables representing the presence and extent of the laws in each state. As of 2013, less than half of the states (18) plus DC allow CNMs to practice with no barriers to care, while the rest of the states require some form of oversight or collaborative practice agreement. Figures 1 and 2 shows maps of the CNM SOP laws by state for 1994 and 2013 and demonstrate the variation in our sample across states and over time. Less restrictive SOP laws were not always in place, with states only recently eliminating barriers to care, and in a few cases states have tightened restrictions. Using a long time period allows us to observe continued variation and such variation is critical to our research methodology described below.

\section{Mechanisms of Change}

Moving from a restrictive practice environment to a less restrictive one can affect health care markets through both the supply of CNMs and the demand for their services. On the supply side, the effects of the different SOP laws may work through altered incentives for entry into the 
profession or workplace, or through migration, where workers move to areas with more favorable practice environments. On the demand side, the laws may have a number of effects. Less restrictive laws with no oversight requirements may encourage the opening of new health care facilities staffed primarily by APRNs, or in our case, new birthing centers staffed by CNMs. Expanded allowable services such as the ability to prescribe may alter consumers' "tastes" for seeing APRNs and again, lead to increased demand for their services. Ancillary effects may be to bring people into the market that may have otherwise forgone or delayed care, or to generate a substitution away from physician services. Even without expanding the supply of nurses or the demand for new nurse-staffed facilities, eliminating oversight requirements that generate delays in care may improve the marginal productivity of practicing nurses. In theory, all of these effects should increase the equilibrium number of nurses practicing in less restrictive SOP environments, while the effect on wages is ambiguous.

While changes in the laws may induce changes in the rates of use of CNMs, or changes in the practice of medicine by CNMs, it is unknown how this ultimately will affect the quality of care. Proponents of fully enabled SOP argue that by design, the CNM model of care improves maternal and infant health outcomes by emphasizing and supporting prenatal care and through the use of less medical technology. The implication here is that any policy that expands the use of CNMs will result in more healthy pregnancies and improved birth outcomes. The counter argument is that the shorter length of training and clinical experience required for CNMs may result in an overall lower quality of care, and that expanded use of CNMs will have a deleterious effect on the health outcomes. To complicate matters, it is also possible there are spillover effects in that the presence of new providers could help alleviate shortages, alter wait times and time spent with patients, potentially leading to improved health outcomes from all providers. 
Another possibility is that the threat of competition from alternative providers could influence the physician practice.

We argue that both obstetricians and CNMs support the production of "good health" via the inputs, although the input mix is different and for CNMs includes more time and less medical technology. Whether the SOP laws affect the overall production of good health in a meaningful way is an empirical question that we address here by evaluating the effects of changes in the SOP laws for CNMs on: 1) altering maternal prenatal health behaviors (timely prenatal care, tobacco use, alcohol use, appropriate weight gain); 2) altering labor and delivery outcomes (labor induction, C-section birth); and 3) altering infant health outcomes (birth weight, gestational age at birth, birth injury). Note that for the infant health outcomes of birth weight and gestational age, the effects of the CNM SOP laws would work via changes in health inputs, only some of which we can observe such as early prenatal care, lower tobacco and alcohol use, appropriate gestational weight gain and method of delivery. Our main focus and conclusions arise from the estimation of health/behavior outcomes and labor/delivery outcomes, but we supplement with analyses of the employment level of nurses and choice of delivery attendant to shed some light on the mechanisms. The data and estimation techniques for each set of outcomes are described below.

\section{Data and Methods}

Health Outcomes Estimation: We use a multi-state, multi-time period difference-in-differences methodology to evaluate the effects of the varying SOP laws on the outcomes of interest. This approach is advantageous in that it allows for a comparison within a state before and after the SOP law changes, while netting out similar trends in states that do not experience law changes. 
Our research design avoids some of the flaws present in the previous cross-sectional studies; in particular, we have valid pre-law and post-law time periods along with valid treatment and control groups and are able to separate out the true effect of the policy changes from confounding national and state-specific trends. Using data from birth certificates (described below) our primary equation of interest evaluates the effects of the SOP laws on health outcomes as follows:

$$
H_{i c j t}=\beta_{1} C N M-S O P_{j(t-g)}+\beta_{2} X_{i c j t}+\beta_{3} Z_{c j t}+\delta_{j}+\gamma_{(t-g)}+\varepsilon_{j t}
$$

In equation 1a, $\mathrm{H}$ represents the health outcomes for individual (i) in county (c) in state (j) at time (t). $C N M-S O P$ are indicator variables for the scope of practice laws pertaining to certified nurse midwives in effect in the state at the time of conception (t-g) where $\mathrm{g}$ is gestation length as documented in the vital records. We use the category of "No barriers" as the omitted reference group in order to easily show how all other levels of restrictions compare to this category. The vector $X$ contains maternal characteristics available on the birth certificates including age, marital status, maternal education, race/ethnicity and county population size; $Z$ represents county-level factors that may also influence the markets for or practice of nurses, including the number of primary care physicians per capita (including obstetricians and family practitioners), real income per capita, the unemployment rate, and the poverty rate; $\delta_{j}$ and $\gamma_{t}$ represent state fixed effects and conception year-by-quarter fixed effects, respectively. Geographic codes on the birth certificates allow us to identify the county in which the mother resides, unless the county is very small $(<100,000$ population). For the variables in the $\mathrm{Z}$ vector for which we do not know the county, we use the average value for all counties in that state with population less than 100,000 .

The estimation of Equation 1a provides a direct comparison of health outcomes for all births under the different SOP law regimes. Evaluating the effects among all babies born to all 
attendants is important particularly if the laws alleviate shortages and allow for improved care by physicians. Stange (2014) provides some support for this idea by showing an increase in primary care utilization in areas where nurse practitioners can prescribe controlled substances.

We estimate a second equation similar to 1a that limits births to those that are attended by a CNM:

$$
H_{i c j t}=\beta_{1} C N M-S O P_{j(t-g)}+\beta_{2} X_{i c j t}+\beta_{3} Z_{c j t}+\delta_{j}+\gamma_{(t-g)}+\varepsilon_{j t} \text { for } C N M_{i c j t}=1 .
$$

Estimation of equation $1 \mathrm{~b}$ provides a direct comparison of health outcomes among CNM attended births under the different SOP law regimes. This equation provides the most direct evidence on outcomes associated with the providers that are specifically targeted by the laws. We caution that the results of estimating Equation $1 \mathrm{~b}$ are only suggestive since there are many known limitations to the attendant variable drawn from the birth certificates, including underreporting of CNMs. Walker et al. (2004) estimates that underreporting is around 11 percent in a small sample of births in Michigan. The attendant recorded is defined as "the individual physically present at the delivery who was responsible for the delivery." (NCHS 2016); the NCHS guide gives the example that if a CNM delivers the baby under the supervision of an obstetrician who is present in the room, the obstetrician should be reported as the attendant. This leaves open the possibility that the attendant recorded is systematically related to the SOP laws, especially in supervisory states. Another potential issue is that the attendant recorded also does not necessarily indicate the prenatal care provider. Given these issues, the results from this equation are not the primary focus of the paper.

Health Outcomes Data: Data on maternal and infant health outcomes for our analyses come from the Center for Disease Control's National Vital Statistics System Birth Certificates. We 
examine outcomes pertaining to different aspects of pregnancy, labor, and delivery. The first group of outcomes is maternal health behaviors which includes indicators for receiving first trimester prenatal care, tobacco use during pregnancy, alcohol use during pregnancy, and an indicator for adequate weight gain during pregnancy. The question regarding alcohol consumption was eliminated from the birth certifications as of 2007 so results for this outcome are limited to 1994-2006.

The second group regards labor and delivery outcomes and includes indicator variables for labor induction versus no induction and $\mathrm{C}$-section versus vaginal birth. We also consider effects of SOP laws on estimates of labor inductions or C-sections for which there are not apparent medical indications. Termed "elective" procedures, we define these labor inductions and $\mathrm{C}$-section deliveries as those without the presence of certain clinical characteristics that might necessitate medical intervention. In choosing these characteristics for this analysis, we are limited by the data elements consistently available on the birth certificates. For labor induction, these characteristics are 1) premature rupture of membranes and 2) chorioamnionitis (inflammation of the fetal membranes due to bacterial infection) or evidence of chorioamnionitis as indicated by the presence of intrapartum fever. For C-sections we use characteristics 1 and 2, and add 3) presentation other than cephalic (any part of the fetus other than the head appearing first) and 4) fetal distress or fetal intolerance of labor. As described in more detail below, we also limit all samples to women with no history of certain pregnancy risk factors.

Lastly we examine infant health outcomes including the following: Birth weight; probability of birth weight less than 2500 grams; gestation weeks; probability of gestation less than 39 weeks; and an indicator variable for birth injury. Birth injury as defined on the birth 
certificate includes skeletal fractures, peripheral nerve injury, and damage to soft tissues or solid organs. These injuries are potentially avoidable in the process of labor and delivery.

We use linear probability models to analyze the dichotomous variables and use OLS to analyze average birth weight and gestational age. Standard errors in all models are adjusted for clustering at the state level. We tested models using probit for the dichotomous outcomes and results and conclusions are unchanged. We also use alternative ways of analyzing birth weights and gestation weeks using ordered probits and quantile regression. These models are discussed further below.

\section{Sampling and Statistical Issues:}

There are a number of sampling concerns that we address. First and foremost, there is concern of sample selection issues where women who have prior knowledge about health outcomes may be more likely to choose or avoid a CNM. To help alleviate this issue, we limit the sample to singleton, first births. We further limit the sample to women with no history of any of four pregnancy risk factors: diabetes (prepregnancy or gestational), eclampsia, chronic hypertension, and pregnancy associated hypertension. These four conditions are chosen because they are the only ones consistently available on the birth certificates during our sample period. These limitations should help generate a more homogeneous sample of women. An additional factor to note is that any prior health knowledge should be uncorrelated with the laws, leaving the reduced form estimates unbiased.

Next, we place some additional restrictions on the sample. We limit sample to women who give birth and reside in the same state in order to ensure a proper match with the laws. For models that use the full sample of births, we use a $25 \%$ random sample of birth certificates based on states to manage computer file size. We also omit births attended by certified midwives 
(midwives who are not APRNs). Over our sample period, only $0.34 \%$ of births are attended by these midwives, while $7.26 \%$ are attended by CNMs. The overwhelming majority (92.4\%) are attended by physicians (MDs and DOs) with the remaining unknown (0.44\%). We do, however, use the universe of births attended by CNMs when estimating Equation 1a.

In addition, the birth certificates underwent revisions in 2003, with the result that some of the variables have changed over time either in form or availability. The revised certificates were phased in over the years, but at different times by different states, and therefore, some variables are missing for some states in a few years. The outcome variables we use that are affected by the 2003 revisions include the following: tobacco use, alcohol use, birth injury, and some of the clinical characteristics used to generate elective inductions and C-sections (premature rupture of membranes, chorioamnionitis, presence of fever, fetal distress, fetal intolerance of labor). The results shown below use all available data, but the panel will be unbalanced for these outcomes. However, this should not present a problem for the validity of our estimates since the states and time periods with missing values are not systematically related to the outcomes or the laws and is likely to be uncorrelated with the error term. We did test models where restrict the sample to only the states that have non-missing values in all years and results are similar to those presented below (available upon request).

Policy endogeneity is another potential concern. This endogeneity can be either statistical (correlation with the error term) or structural (when laws are altered as a result of the outcomes under consideration). The county level variables and the state and year fixed effects should help alleviate statistical endogeneity. Structural endogeneity is unlikely to be an issue. Is hard to argue that the individual outcomes we examine would influence SOP policies, especially since the laws pertaining to CNMs are also often passed in conjunction with laws pertaining to 
all APRNs. Miller (2006) discusses this issue in her paper and finds that the timing of insurance reimbursement mandates for CNMs supports the exogeneity of these laws.

In all our models, the values on the SOP law coefficients are used to draw the study's main conclusions. These coefficients represent reduced form effects, where the laws influence health outcomes through the variety of pathways previously mentioned. The empirical analyses illuminate the magnitude and direction of any effects. Coefficients on health outcomes that are small and statistically indistinguishable from zero reflect no difference in health outcomes based on restrictiveness of the laws. Statistically significant positive or negative coefficients are interpreted accordingly, with explanations for these effects being drawn from the study of possible pathways as described next.

\section{Pathways:}

Recall that the arguments for altered health outcomes stems in part from the expanded use of CNMs as a result of the less restrictive laws which can work through altered labor supply, altered demand for services and new facilities and perhaps via improved marginal productivity of the CNM workforce. Unfortunately, the available data do not allow us to study all of the possible pathways in depth, but we are able to examine effects on measures of the employment levels of CNMs, on the demand for nurse services by observing the choice between physicians and CNMs attendant, and on changes in the probability of births occurring at freestanding birth centers.

The estimating equation for the employment levels of nurses takes the following general form:

$$
S_{j y}=\beta_{1} C N M-S O P_{j y-1}+\beta_{2} L_{j t}+\delta_{j}+\delta_{y}+\varepsilon_{j t}
$$


where $S$ is a measure of the number of CNMs per 100,000 women of child-bearing age in state (j) in year (y), CNM-SOP represents the scope of practice laws for oversight and prescription authority lagged one year so as to help avoid reverse causality from the workforce to the laws; $L$ is a vector of other factors relevant to the labor market for nurses and includes the state per capita number of obstetricians and primary care physicians, state unemployment rates, and state real income per capita; and $\delta_{j}$ and $\delta_{y}$ represent state and year fixed effects, respectively. The models are estimated by weighted OLS with the state female child-bearing population (ages 14-44) as the weight and standard errors clustered by state.

Data on the number of nurses come from two different sources. The National Sample Survey of Registered Nurses has estimates of the number of employed nurses for select years. The employment questions pertain to the current survey year and employment status twelve months prior which generates state estimates for 1995, 1996, 1999, 2000, 2003, 2004, 2007 and 2008. Given the limited number of years available from this source we also analyze data from The Nurse Practitioner's annual legislative update. This publication has counts of licensed CNMs from 1999 to 2013, however these counts include employed, unemployed and nurses who are out of the labor force.

Turning to the question of who is chosen as the provider of care, the estimating equation for the choice between a physician and CNM attendant takes the following general form:

$$
A_{i c j t}=\beta_{1} C N M-S O P_{j(t-g)}+\beta_{2} X_{i c j t}+\beta_{3} Z_{c j t}+\delta_{j}+\delta_{(t-g)}+\varepsilon_{j t}
$$

where $A$ represents the probability that a birth was attended by a CNM versus a physician $(\mathrm{MD} / \mathrm{DO})$ as reported on the birth certificates. All other variables are as defined in equation 1a above. We analyze this probability first among our sample of singleton first births with no reported maternal medical risks, and second, among a sample of second or more births, termed 
parity $>1$. We generate this second sample using a $10 \%$ state-based random sample of all nonfirst births and then further restrict this sample to singleton births born to women with no reported maternal medical risks, no prior C-sections, and no prior pre-term births. This second sample will allow us to analyze the provider decision among women who have knowledge of the birthing process and to see if the SOP laws have effects on provider choice among these 'experienced' women. Equation 3 is estimated by a linear probability model and standard errors are clustered by state. Probit models yield identical results.

As we discuss above, we caution that the results of estimating Equation 3 are only suggestive due to the issues with the attendant variable on the birth certificates. A further limitation of this particular analysis is that the results do not help shed much light on the mechanism behind the choice of CNMs vs. physicians. Results can reflect changes in the supply of CNMs available for attending births and/or changing tastes for using a CNM, and we cannot distinguish between the two. At best, the results of this exercise will simply tell whether or not the laws have a statistical association with the attendant of record on the birth certificates.

Another way to measure changes in demand for services and new facilities staffed by CNMs is to examine changes over time in the number of births occurring in freestanding birth centers (FBC). A birth center is a "home-like facility existing within a healthcare system with a program of care designed in the wellness model of pregnancy and birth" (AABC 2016). Birth centers employ physicians, CNMs, and certified midwives, but the facilities are designed around the midwifery model of care. The number of FBCs has grown over time in recent years, increasing from 195 centers nationwide in 2008 to 320 in 2016 (AABC personal communication). The birth certificates contain information on the place where the birth occurred, enabling us to analyze the probability of giving birth in a $\mathrm{FBC}$ versus a hospital. We 
exclude home births and other locations since these may be planned or unplanned. We first analyze this probability among our sample of singleton first births with no reported maternal medical risks, and second, among the sample of singleton second or more births described above. The estimating equation is similar to equation 3 above, however, we analyze the probability of a FBC birth for births attended by all practitioners, including certified midwives, in order to examine the demand for the facility type rather than the practitioner type. Because of the very small proportion of births at FBCs, we use probit to estimate the models. Standard errors are again adjusted for clustering at the state level.

\section{Medically Underserved Areas}

Using the individual level birth outcomes data also enable us to evaluate the effects among vulnerable populations, including mothers residing in medically underserved counties. Indeed, the debate over fully enabled SOP is particularly salient for these women, as access to care and the alleviation of shortages have been used as arguments in support of the less restrictive laws. We use the geographic codes on the birth certificates to help identify medically underserved areas. The Health Resources and Services Administration of the U.S. Department of Health and Human Services describes a method for identifying medically underserved areas (see details at http://www.hrsa.gov/shortage/mua/index.html). Using their methodology and annual data from the Area Health Resource File, we generate the Index of Medical Underservice. This index is based on weighted averages of four variables: the ratio of primary care physicians to population, the poverty rate, the percent of people age $65+$, and the infant mortality rate. The index ranges from 0 to 100 , with the degree of underservice falling as the index rises. HRSA designates areas with an index value of 62 or less as a medically underserved area (MUA). The 
value of the index fluctuates year to year, often hovering around the cut-off point. In order to keep a consistent sample of counties, we use the cut-off point to identify mothers living in counties that ever had a MUA designation over the years 1994-2013. When the mother lives in an unidentified small county, the state average index value for all small counties in the state and year is used to determine the MUA designation. In most cases these small population counties are designated as MUA, but in two states, New Hampshire and Rhode Island, they are not.

Limiting the sample to births by mothers living in counties that ever had a MUA designation, we re-run equations $1 \mathrm{a}, 1 \mathrm{~b}$ and 3 using the methods described above, although we exclude the per capita number of physicians and the poverty rate from the $Z$ vector since these two variables are used in the MUA index. We also test some additional models where we recreate the index using the ratio of obstetricians/gynecologists to the female population ages 1544 rather than the ratio of primary care physicians to total population. The results are similar and are available upon request. We use the index based on primary care physicians rather than obstetricians/gynecologists since primary care physicians may often serve as the provider in cases of labor and delivery especially in medically underserved areas.

\section{Summary Statistics}

Table 2 shows means of all variables for our main estimation sample (column 1) and by attendant type (columns 2 and 3). The first set of rows in the table shows differences in the characteristics of women who use physicians (MDs and DOs) versus CNMs. Women who use CNMs are slightly younger (23.68 years versus 24.92 years), less likely to be married (49 percent versus 56 percent), more likely to be Native American (2 percent versus 1 percent) and Hispanic ( 24 percent versus 20 percent), and less educated. The county characteristics based on birth 
attendant are very similar, although women using CNMs are slightly less likely to live in counties that ever received a medically underserved designation.

Table 2 also shows means of the health outcomes by attendant at birth. While rates of early prenatal care are more favorable under the physician attendant than CNM, other maternal health behaviors are similar for each attendant type. Not surprisingly, physician attended births are more likely than CNM births to be induced although induction is not uncommon for either provider (22\% and $18 \%$ of births, respectively). CNMs are not trained to perform $\mathrm{C}$-sections, nor are they legally allowed to perform this procedure. Therefore we should see a zero for Csections under the CNM birth attendant column. The proportion presented $(0.01)$ is close to, but not equal to zero, indicating some of the misreporting of attendant that occurs on the birth certificates. Lastly, Table 2 shows that infant birth outcomes are more favorable under CNM delivery. Even though these means include the restrictions limiting the sample to singleton first births with no reported maternal medical risks, these differences in means are only suggestive as these are unadjusted for maternal and area characteristics.

Table 3 shows unadjusted means in the health outcomes based on the categories of SOP laws. In general, birth outcomes are similar in all types of practice environments. There are noticeable differences across the SOP law categories in the receipt of first trimester prenatal care with the highest proportion occurring in high barrier states. By contrast, these high barrier states also have the highest rates of smoking during pregnancy. Alcohol consumption is similar in all states, as is the proportion of women with adequate weight gain. Rates of labor induction are the lowest in the high barrier states at 18 percent, compared with the no barrier states at 22 percent. Rates of C-sections among the no barrier and high barrier states are both lower than the other states with rates of 24 percent. The average birth weight is highest in the no barrier and low 
barrier states, while the other birth outcomes are very similar across all states. Lastly, the percent of births is not distributed evenly, with the highest proportion occurring in moderate barrier states. Not surprisingly, the most CNM births occur in no barrier states, but what is surprising is that the proportion here (10 percent) is only slightly higher than that of the high barrier states with 9 percent. The middle two categories both have 6 percent of births attended by CNMs.

\section{Results for Prenatal Health Behaviors, Delivery, and Birth Outcomes}

Tables $4 a, 4 b$ and $4 c$ contain results from the maternal health behaviors, labor and delivery outcomes, and infant health outcomes, respectively, among all providers. The results in Table 4a show no difference in maternal health behaviors based on the category of law. By contrast, the results in Table $4 \mathrm{~b}$ show that women giving birth in high barrier states are 3.0 percentage points more likely to be induced, and 1.6 percentage points more likely to have a Csection compared to women in states with no barriers. Women in the moderate barrier states are also more likely to be induced or have a C-section compared to women in states with no barriers, although the coefficient on induction is statistically significant at just above the 10 percent level. The effects for the low level of barriers are not statistically different from the barrier-free states. The results for the apparent elective inductions and C-sections tell a similar story, with low-risk women in moderate and high barrier states more likely to have $\mathrm{C}$-sections relative to the no barrier states.

To put the magnitude of the C-section effects into context, moving from high barrier to no barrier represents a reduction in the $\mathrm{C}$-section rate from $25.3 \%$ to $23.7 \%$ (a $6.3 \%$ reduction). Considering there are currently around 1.3 million first births per year, this $6.3 \%$ reduction 
equals approximately 20,800 C-sections avoided annually. Using data from the MEPS we calculate a $\$ 4,099$ difference in the amounts paid for C-section versus vaginal delivery. This implies a savings of over $\$ 85$ million a year. According to a report by Truven Health Analytics, the estimated difference between $\mathrm{C}$-section and vaginal delivery is $\$ 9,372$ for mothers and infants with employer provided commercial insurance, indicating that these payers could save even more per delivery under less restrictive SOP laws for CNMs (Truven Health Analytics 2013).

In considering the infant health outcomes, Table $4 \mathrm{c}$ reveals little in the way of systemic differences based on the SOP law classification. Average birth weights are slightly lower in the states with barriers compared to the states with no barriers, but by very small amounts ( 6.3 grams for low barriers, 11.3 grams for moderate barriers and 9.1 grams for high barriers). At an average birth weight of 3,286 grams, these effects seem too small to be meaningful and indeed only the moderate SOP coefficient is statistically significant. Columns 2 show results for the probability of birth weight $<2500$ grams, but there are no discernable effects of the laws on this outcome. Column 3 shows that the average gestation length is slightly reduced by about 0.06 weeks (less than half of a day) in moderate and high barrier states, but again, this effect is very small considering an average gestation of 39 weeks. Column 4 also shows that the probability of an early birth ( $<39$ weeks' gestation) is higher in the high barrier states by 1.2 percentage points. Column 5 considers the probability of observing an injury at birth but here the laws have no statistically significant effects. Overall, the results in Table $4 \mathrm{c}$ indicates that the laws are neither helpful nor harmful when it comes to infant health.

Looking at changes in average birth weight and weeks of gestation may mask some of the effects that might occur at other parts of the distribution. To check for this, we first run an 
ordered probit on categories of gestation weeks. We group the weeks into classifications designated by the American College of Obstetrics and Gynecology (2013): <34 complete weeks (early preterm), 34 through 36 completed weeks (late preterm), 37 through 38 completed weeks (early term), 39 through 40 completed weeks (term) and 41 or more weeks (late term and post term). Ordered probit results indicate that the laws reflecting moderate and high barriers reduced the probability of having a term birth (39-40 weeks and $41+$ weeks) and increase the probability of births in the all categories that are less than 39 weeks. Again, the size of the effects are very small relative to the means. For example, the statistically significant probability changes associated with the high barrier states are as follows: -0.010 (41+ weeks), -0.002 (39-40 weeks), 0.006 (37-38 weeks), 0.004 (34-36 weeks), 0.002 ( $<34$ weeks). These effects should be interpreted relative to the baseline probability of each category: 0.206 (41+ weeks), 0.484 (3940 weeks), 0.216 (37-38 weeks), 0.067 (34-36 weeks), 0.027 ( $<34$ weeks).

Although small in magnitude, the result that SOP laws can influence gestation weeks may be surprising given that altering gestational age is generally very difficult to do, and especially given that we see no changes in maternal health behaviors, including smoking. However, since the laws' effects occur around the 39 week mark, we believe that these gestation results are most likely reflecting the results shown above for labor inductions and C-sections. Where the barrierfree SOP lower rates of these procedures, we may plausibly see longer gestation periods on average as more women avoid the elective procedures.

Ordered probits for categories of birth weight show no statistically effects of the laws on the probability of being in one of three birth weight categories: normal weight, low birth weight ( $<2500$ grams -1500 grams), or very low birth weight $(<1500$ grams. $)$ However, these cut-off points may be too broad to detect meaningful results, so we turn to a unconditional quantile 
regression to check for effects across the distribution of birth weights (Firpo et al. 2009; Borah and Basu 2013; Borgen 2016). Figure 3 shows the effects of the SOP laws on the $5^{\text {th }}$ through $95^{\text {th }}$ quantiles of birth weights. Coefficients for all three laws are plotted, and statistical significance of each point estimate is indicated by the shading of the marker. For the bulk of the quantiles (the $15^{\text {th }}$ through $65^{\text {th }}$ quantiles), the effects of the laws are statistically indistinguishable from zero. The effects of the laws on average birth weights seen in Table $4 \mathrm{c}$ seem to be driven by effects at the top of the distribution. The birth weights associated with the higher quantiles range from 3555 grams to 4111 grams ( $7.8 \mathrm{lbs}$ to $9.1 \mathrm{lbs}$ ) and the reductions associated with the laws range from 8 to 21 grams $(0.02 \mathrm{lbs}$ to $0.05 \mathrm{lbs})$. In other words, the SOP restrictions are only influencing the birth weights of infants with higher birth weights and by only a small amount. For many infants, variations in weight of these magnitudes are not a health concern, however, fetal macrosomia is a concern and if SOP barriers reduce birth weights among the heaviest of babies this may be seen as health improving.

\section{$\underline{\text { CNM Attended Births }}$}

Table 5 limits the sample to deliveries attended by CNMs only, and reflects the women whose prenatal care and delivery were most likely managed by a CNM. Hence, it provides the most direct information on the effects of SOP laws for CNMs with the caveats mentioned above about the issues surrounding the reported attendant on the birth certificates. Here, we find a higher probability of drinking during pregnancy in low barrier SOP states, although we also see an unexpected result where smoking rates are lower in the high barrier SOP states (at the 10 percent significance level). In addition, we see more adverse birth outcomes in the groups of states with barriers including higher rates of labor induction (in moderate and high barrier states), 
lower average birth weight (in low and moderate barrier states states), and slightly lower gestation weeks in all states with barriers. However, the magnitude of the reductions are again very small for gestation weeks and birth weight.

Analyses using ordered probit to analyze the five categories of gestational age at birth and the three categories of birth weight for births attended by CNM generate results similar to that for the larger sample of physician/CNM attendants. The laws have statistically significant, but very small effects on gestational age at birth, with the barriers associated with a reduction in the probabilities of $39-40$ weeks and 41 or more weeks. The laws have no statistically significant effects of the probabilities of low or very low birth weight. The unconditional quantile regression results show no statistical difference between high barrier SOP states and no barrier states in terms of birth weights, however, there are negative effects of moderate and low levels of barriers on birth weights beginning at the $45^{\text {th }}$ and $50^{\text {th }}$ percentiles, respectively. The magnitudes range from 6 grams to 20 grams.

\section{Medically Underserved Areas}

Tables $6 \mathrm{a}, 6 \mathrm{~b}, 6 \mathrm{c}$, and 7 are similar to Tables $4 \mathrm{a}, 4 \mathrm{~b}, 4 \mathrm{c}$, and 5 but the samples are limited to women residing in counties that are identified as medically underserved any time during the sample period. Tables $6 \mathrm{a}-6 \mathrm{c}$ shows results for physician and CNM attendants combined and Table 7 limits the sample to only CNM attended births. Overall, the results are consistent with that of the previous tables. There are no large statistical differences in maternal health behaviors based on the laws. However, here we also see no observed differences in the probability of a Csection. Rates of labor induction are higher in medically underserved counties located in moderate and high barrier states ( 4.9 and 2.5 percentage points for all attendants in Table $6 \mathrm{~b} ; 5.9$ 
and 4.0 percentage points for $\mathrm{CNM}$ attendants in Table 7) compared to no barrier states. We also observe lower gestational age in low barrier states (Table $6 \mathrm{c}$ and Table 7) and in moderate barrier states (Table 7) compared to no barrier states. Ordered probits confirm these results with the negative effects of the barriers occurring at $39-40$ weeks and $41+$ weeks. Average birth weight is also slightly lower in low barrier states attended by CNMs in medically underserved counties, but there are no effects on the probabilities of low and very low birth weights.

\section{Results for Mechanisms}

Results for employment levels are shown in Table 8. Here, we show results from 1) annual estimates of number of licensed CNMs by state for 1999-2013 per 100,000 women ages 14 to 44; and 2) annual estimates of number of employed CNMs by state per 100,000 women ages 14 to 44 for 1995, 1996, 1999, 2000, 2003, 2004, 2007, and 2008. Models include alternatively one year lags and three year lags in the laws in order to allow the laws time to affect labor markets. We use a three year lag because three years is the average time it takes to complete an advanced nursing degree. However, weighted OLS regressions of these employment measures yield small and statistically insignificant coefficients on all the law categories.

Table 9 examines the effects of the laws on the probability of having a birth attended by a CNM versus a physician. Results are shown for all counties (columns 1 and 3) and medically underserved counties (columns 2 and 4), among first births (columns 1 and 2) and parity $>1$ (i.e. second or more births, shown in columns 3 and 4). Among all counties, the probability of delivery by a CNM is lower in moderate and high barrier states by a range of 1.4 to 2 percentage points. This is a fairly large effect given that only 7.5 percent of our sample of births are 
reported as attended by CNMs. The results for medically underserved areas show no difference in the probability of a CNM attendant based on the degrees of barriers to practice although the signs of the coefficients are negative for all types of barriers. These results provides some evidence that eliminating barriers to practice acts on the demand for CNMs by women, rather than through some of the possible labor market channels. We again caution that attendant type is recorded with a lot of known issues, so these results should be taken as suggestive only.

Lastly, Table 10 shows probit results for the choice of delivering in a freestanding birth center versus a hospital for all counties (column 1 and 3) and medically underserved counties (column 2 and 4), for first births (columns 1 and 2) and second or more births (columns 3 and 4). The SOP coefficients are negative in most models shown, and are statistically significant for moderate barriers in all models and high barriers in columns 2,3 , and 4 . The probability of delivering in a FBC is very rare with 0.26 percent of the sample of first births born in FBCs among all counties, and 0.27 percent born in medically underserved counties. The proportion is higher for second or more births with the respective proportions at 0.45 percent and 0.57 . Relative to these mean values, the marginal effects are also very small, translating to reductions of less than one percent in all counties, and less than 2 percent in medically underserved counties. Nevertheless, differences in the cost of vaginal births at these lower-cost facilities versus hospitals would add to the calculation of cost savings at time of delivery.

\section{Conclusions}

Overall, the results of our empirical analyses show very few effects of the SOP laws on maternal health behaviors and infant health outcomes based on the degree of barriers to practice imposed by states' SOP laws. We do show, however, that states that allow CNMs to practice 
with no barriers have lower observed probabilities of labor inductions, C-sections, apparent elective inductions, and apparent elective $\mathrm{C}$-sections relative to states with high barriers. We also show some reductions in the probability of induction in the barrier-free states in medically underserved counties. We see very small changes in birth weights and gestational age at birth, but no corresponding change in maternal health behaviors.

Taken together, these results are somewhat puzzling. It is unclear why we see comparatively large changes in C-sections and inductions, but very small or no changes in all other outcomes studied. Our analyses of the mechanisms can provide some insight. We show no effects of the laws on employment levels, however, we do find that the barrier-free status is associated with a small but statistically significant increase use of CNMs as birth attendants, along with a small increase in the use of freestanding birth centers. If we take the results for the mechanisms at face value, this suggests that the CNM labor market is unaffected by the laws, whereas consumer demand for CNM services is influenced. However, we caution that we do not have the available data to learn whether the laws have influenced rate of entry into the profession and we see this as an important direction for future research. Also, the results for employment levels reflect an annual mix of entry, exit, and migration, and while our results point to the conclusion that the effects of the laws on these net changes is zero, we cannot separate out the different movements here.

Our results lead to a competition story. The popularity of CNM services is growing, with the proportion of CNM attended singleton births (of any parity) increasing from 5.3 percent in 1994 to 8.4 percent in 2013. Whereas the growth of CNM use is likely not large enough to bring about noticeable changes in the averages of many of the outcomes we study, our results are consistent with a story where the obstetric practices are changing in response to the threat of 
competition from CNM services that are formally untethered to the physician practice. (It should be noted that it is standard practice for CNMs under any SOP environment to work collaboratively with physicians.) This may explain why the primary results seen are a reductions in labor induction, $\mathrm{C}$-sections and apparently elective labor induction and $\mathrm{C}$-sections. All of these procedures are most directly and immediately affected by the different practitioner approaches to labor and delivery.

Even though we are not fully informed about the exact mechanisms through which the SOP laws are working, our results do directly address the debate surrounding the states' policies regarding SOP for CNMs. Returning to the key arguments we discussed earlier-that critics say the quality of care may suffer while the proponents argue that the efficiency of the system can be improved - means the controversy lies in the determination of the costs and benefits. Our results point to the conclusion that removing barriers on the CNM practice will not harm mothers and infants, and that the restrictive laws primarily serve as artificial barriers to care. We have shown no evidence of deleterious health effects, and in fact show very small improvements in gestational age at birth, likely driven by the reductions in C-sections and inductions prior to 39 weeks' gestation. If the mechanism behind our results is the threat of competition, then there is an efficiency argument to be made for removing SOP-based barriers to practice for certified nurse midwives. 


\section{References}

American Academy of Family Physicians (AAFP). Primary care for the 21st century: ensuring a quality physician-led team for every patient. American Academy of Family Physicians. September 18, 2012.

American Association of Birth Centers (AABC). "What is a Birth Center?" Available at http://www.birthcenters.org/?page=bce_what_is_a_bc. Accessed September 2016.

American College of Obstetricians and Gynecologists (ACOG). Definition of term pregnancy. Committee Opinion No. 579. Obstet Gynecol 2013;122:1139-40.

Anderson, D. Mark, Ryan Brown, Kerwin Kofi Charles, Daniel I. Rees, "The Effect of Occupational Licensing on Consumer Welfare: Early Midwifery Laws and Maternal Mortality" NBER Working Paper No. 22456, July 2016.

Borah BJ and Basu A. "Highlighting differences between conditional and unconditional quantile regression approaches through an application to assess medication adherence. Health Economics. 2013 Sep;22(9):1052-70.

Borgen, Nicolai T. "Fixed effects in unconditional quantile regression." Stata Journal 16.2 (2016): 403-415.

Bureau of Labor Statistics. Occupational Outlook Handbook: Healthcare Occupations. Available at: http://www.bls.gov/ooh/healthcare/home.htm. Publish Date: Thursday, December $17,2015$.

Bureau of Labor Statistics. Data on certifications and licenses. Available at: http://www.bls.gov/cps/certifications-and-licenses-table-5.htm. Accessed Sept. 12016.

Bryson, Alex, and Morris M. Kleiner. "The regulation of occupations." British Journal of Industrial Relations 48.4 (2010): 670-675.

Chambliss, L. R., Daly, C., Medearis, A. L., Ames, M., Kayne, M., \& Paul, R. (1992). The role of selection bias in comparing cesarean birth rates between physician and midwifery management. Obstetrics and Gynecology, 80, 161-165.

Cragin, L., \& Kennedy, H. P. (2006). Linking obstetric and midwifery practice with optimal outcomes. Journal of Obstetric, Gynecologic, and Neonatal Nursing, 35, 779-785.

Davis, L. G., Riedmann, G. L., Sapiro, M., Minogue, J. P., \& Kazer, R. R. (1994).Cesarean section rates in low-risk private patients managed by certified nurse-midwives and obstetricians. Journal of Nurse-Midwifery, 39, 91-97.

DeLano, C. F., Hirsh, L. D., \& Schauberger, C. W. (1997). Nurse-midwifery at Gundersen Clinic: A twenty year review. Wisconsin Medical Journal, 96, 37-40. 
Declercq, Eugene R., et al. "State regulation, payment policies, and nurse-midwife services." Health Affairs 17.2 (1998): 190-200.

Heins, H. C., Jr., Nance, N. W., McCarthy, B. J., \& Efird, C. M. (1990). A randomized trial of nurse-midwifery prenatal care to reduce low birth weight. Obstetrics and Gynecology, 75, 341345 .

Heisler, Elayne J. "Physician Supply and the Affordable Care Act," Congressional Research Service Report for Congress, January 15, 2013, http://op.bna.com/hl.nsf/id/myon93zpre/\$File/crsdoctor.pdf (accessed January 23, 2014).

Firpo, Sergio, Nicole M. Fortin, and Thomas Lemieux. "Unconditional quantile regressions." Econometrica 77.3 (2009): 953-973.

Gittleman, Maury, Mark A. Klee, and Morris M. Kleiner. "Analyzing the labor market outcomes of occupational licensing.” No. w20961. National Bureau of Economic Research, 2015.

Jackson, D. J., Lang, J. M., Ecker, J., Swartz, W. H., \& Heeren, T. (2003a). "Impact of collaborative management and early admission in labor on method of delivery." Journal of Obstetric, Gynecologic, and Neonatal Nursing, 32, 147-157.

Jackson, D. J., Lang, J. M., Swartz, W. H., Ganiats, T. G., Fullerton, J., Ecker, J., et al. (2003b). Outcomes, safety, and resource utilization in a collaborative care birth center program compared with traditional physician-based perinatal care. American Journal of Public Health, 93, 9991006.

Johantgen M, Fountain L, Zangaro G, Newhouse R, Stanik-Hutt J, White K. "Comparison of labor and delivery care provided by certified nurse-midwives and physicians: a systematic review." Women's Health Issues. 2012; 22(1):e73-e81.

Kleiner, Morris M., Allison Marier, Kyoung Won Park, and Coady Wing. "Relaxing Occupational Licensing Requirements: Analyzing Wages and Prices for a Medical Service" Journal of Law and Economics, Vol. 59, No. 2, May 2016

Kleiner, Morris M and Alan B. Krueger. "The Prevalence and Effects of Occupational Licensing," British Journal of Industrial Relations, Vol.48, No. 4 December 2010, pp. 676687.

Kleiner, Morris M and Alan B. Krueger. "Analyzing the Extent and Influence of Occupational Licensing on the Labor Market" with A. B. Krueger, Journal of Labor Economics, vol. 31, no. S1, April 2013 pp. S-173-202.

Kleiner, MM, Marier, A., Parke, WY, Wing, C. "Relaxing Occupational Licensing Requirements: Analyzing Wages and Prices for a Medical Service". NBER working paper 19906, February 2014. 
Kleiner, Morris M., and Kyoung Won Park. "Battles among licensed occupations: Analyzing government regulations on labor market outcomes for dentists and hygienists." Working paper No. w16560. National Bureau of Economic Research, 2010.

Lenaway, D., Koepsell, T. D., Vaughan, T., van Belle, G., Shy, K., \& Cruz-Uribe, F. (1998). "Evaluation of a public-private certified nurse-midwife maternity program for indigent women." American Journal of Public Health, 88, 675-679.

MacDorman, M. F., \& Singh, G. K. (1998). "Midwifery care, social and medical risk factors, and birth outcomes in the USA." Journal of Epidemiology and Community Health, 52, 310-317.

Miller, Amalia R. "The impact of midwifery-promoting public policies on medical interventions and health outcomes." Advances in Economic Analysis \& Policy 6.1 (2006).

National Center for Health Statistics. Guide to Completing the Facility Worksheets for the Certificate of Live Birth and Report of Fetal Death (2003 revision). Updated May 2016. Available at http://www.cdc.gov/nchs/data/dvs/guidetocompletefacilitywks.pdf

Naylor MD, Kurtzman ET. The role of nurse practitioners in reinventing primary care. Health Affairs. 2010; 29(5):893-899.

Newhouse RP et al. Advanced practice nurse outcomes 1990-2008: a systematic review. Nursing Economics. 2011; 29(5):1-22.

Petterson SM, Liaw WR, Phillips Jr RL, Rabin DL, Meyers DS, Bazemore AW. "Projective US primary care physician workforce needs: 2010-2025." Ann Fam Med. 2012; 10(6):503-509.

Robinson, J. N., Norwitz, E. R., Cohen, A. P., \& Lieberman, E. (2000). "Predictors of episiotomy use at first spontaneous vaginal delivery." Obstetrics and Gynecology, 96, 214-218.

Rosenblatt, R. A., Dobie, S. A., Hart, L. G., Schneeweiss, R., Gould, D., Raine, T. R., et al. (1997). "Interspecialty differences in the obstetric care of low-risk women." American Journal of Public Health, 87, 344-351.

Schiff, M. "The role of nurse practitioners in meeting increasing demand for primary care." National Governors Association. Washington, DC. December 2012.

Spetz, J. Parente, ST, Town, RJ and Bazarko D. "Scope-Of-Practice Laws For Nurse Practitioners Limit Cost Savings That Can Be Achieved In Retail Clinics." Health Affairs, 2013, $32: 11,1977-1984$.

Stange K. "How does provider supply and regulation influence health care markets? Evidence from nurse practitioners and physician assistants." Journal of Health Economics. 2014; 33:127. 
Sze, E. H., Ciarleglio, M., \& Hobbs, G. (2008). "Risk factors associated with anal sphincter tear difference among midwife, private obstetrician, and resident deliveries." International Urogynecology Journal and Pelvic Floor Dysfunction, 19, 1141-1144.

Truven Health Analytics. The Cost of Having a Baby in the United States", Prepared by Truven Health Analytics for Childbirth Connection, Catalyst for Payment Reform, Center for Healthcare Quality and Payment Reform, January, 2013.

Timmons, Edward. "Healthcare License Turf Wars: The Effects of Expanded Nurse Practitioner and Physician Assistant Scope of Practice on Medicaid Patient Access," Mercatus Working Paper Series, January 26, 2016.

Walker DS, Schmunk SB Summers L. "Do birth certificate data accurately reflect the number of CNM-attended births? An exploratory study." J Midwifery Women's Health. 2004; 49:443-448.

Wing, Coady, and Allison Marier. "Effects of occupational regulations on the cost of dental services: evidence from dental insurance claims." Journal of health economics 34 (2014): 131143.

Yang, Y. Tony, Laura B. Attanasio, and Katy B. Kozhimannil. "State scope of practice laws, nurse-midwifery workforce, and childbirth procedures and outcomes." Women's Health Issues 26.3 (2016): 262-267. 
Figure 1: CNM SOP 1994

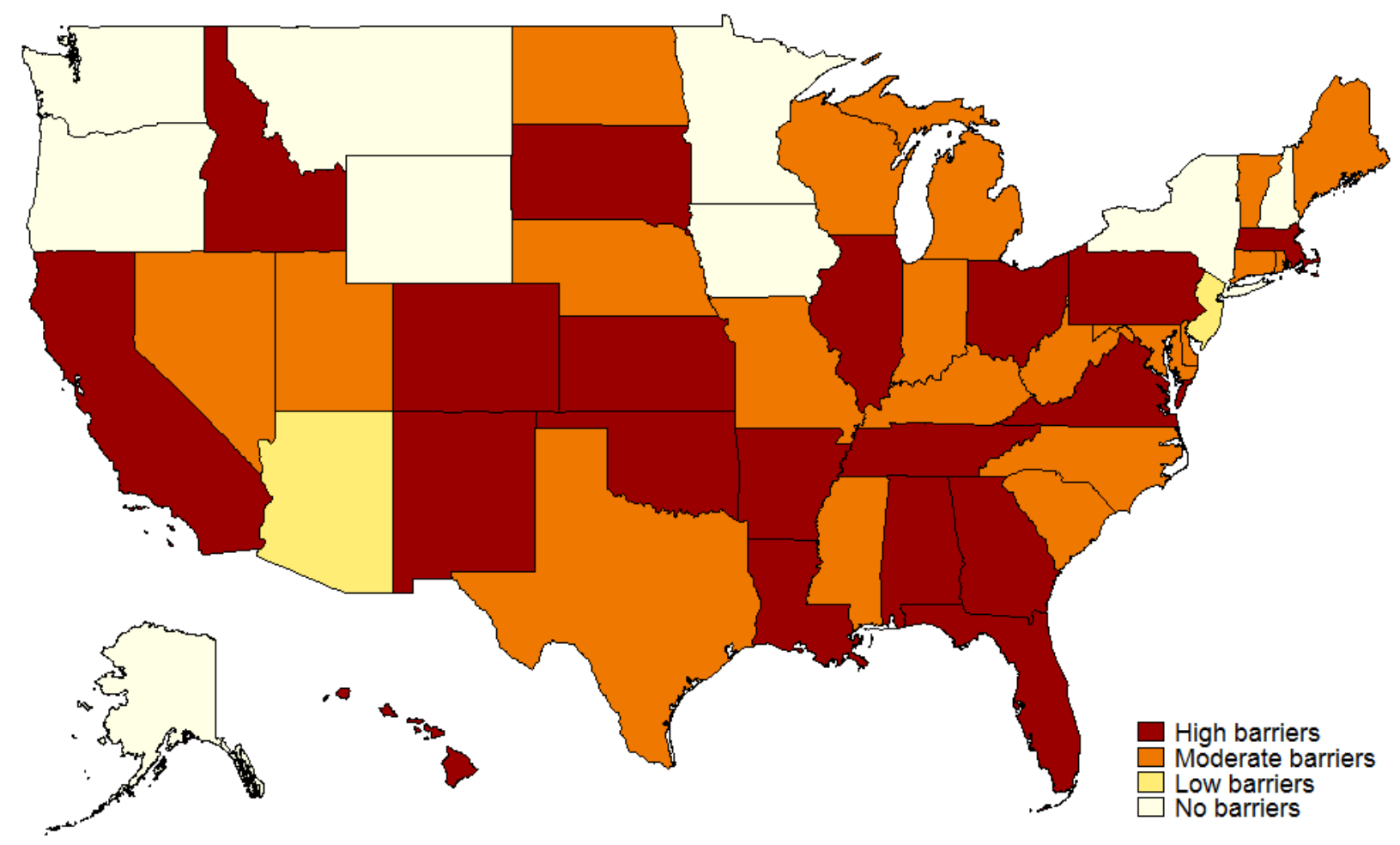

Figure 2: CNM SOP 2013

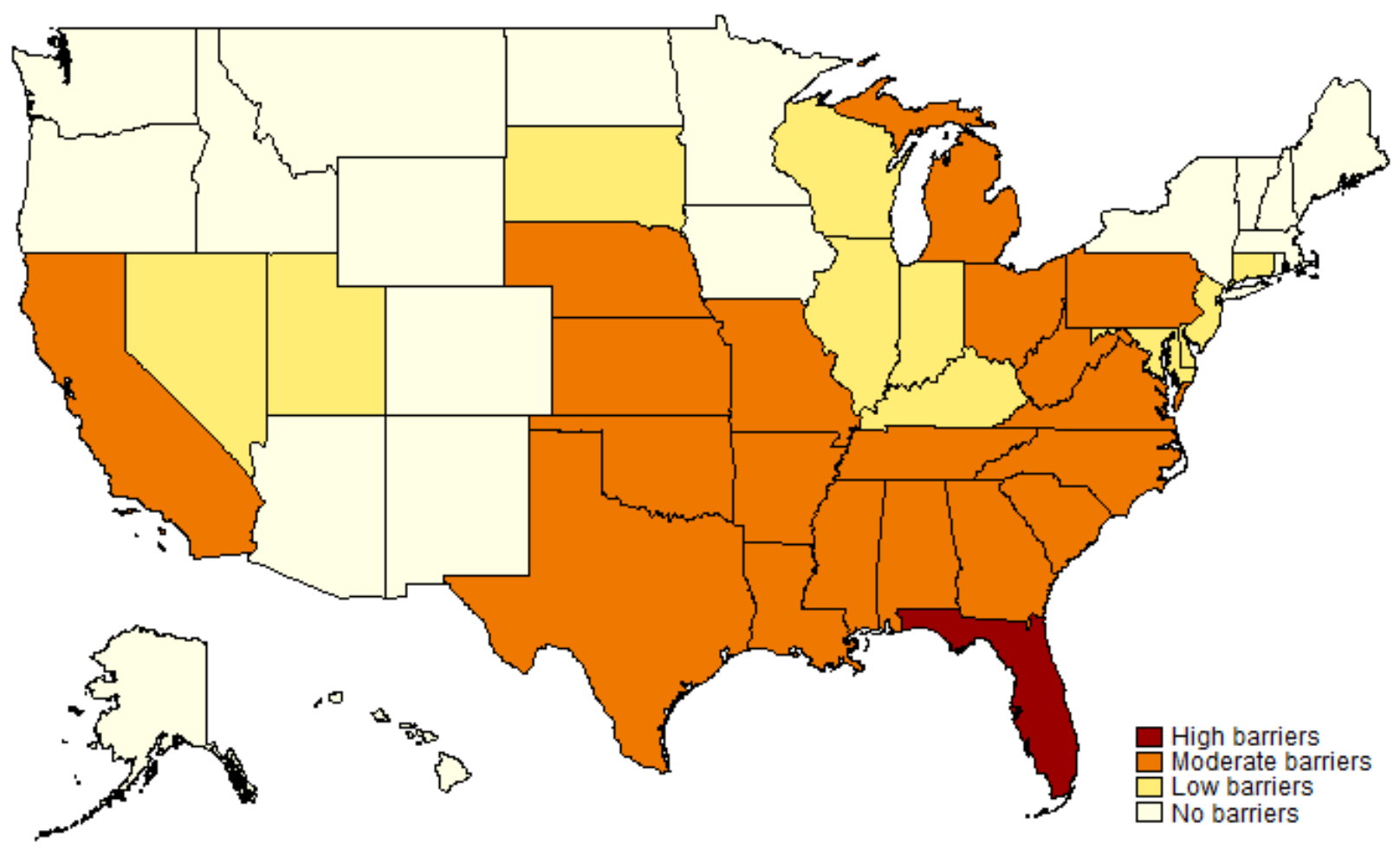




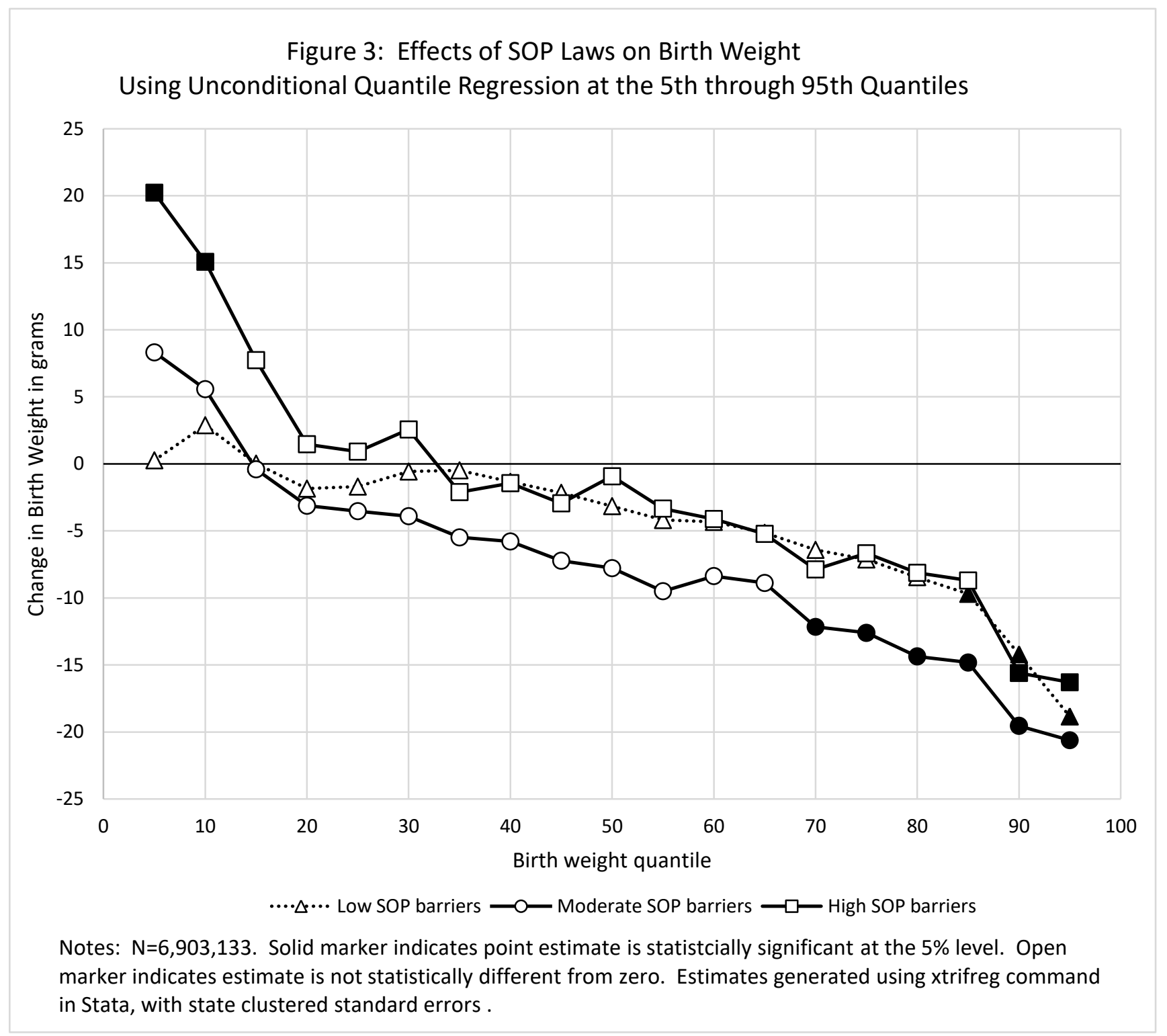




\section{Table 1}

\begin{tabular}{|l|l|l|}
\hline \multicolumn{1}{|c|}{ Study } & \multicolumn{1}{|c|}{$\begin{array}{c}\text { State and data collection } \\
\text { period }\end{array}$} & \multicolumn{1}{c|}{$\begin{array}{c}\text { Scope of Practice Law } \\
\text { classification* }\end{array}$} \\
\hline Chambliss et. al (1992) & Arizona (prior to 1992) & Collaborative \\
\hline Cragin \& Kennedy (2006) & California (years unknown) & Restrictive \\
\hline Davis et al. (1994) & Illinois (1987-1990) & Restrictive \\
\hline Delano et al. (1997) & Wisconsin (1975-1995) & Restrictive \\
\hline Heins et al. (1990) & South Carolina & Restrictive \\
\hline $\begin{array}{l}\text { Jackson et al. (2003a and } \\
\text { 2003b) }\end{array}$ & California (1994-1996) & Restrictive \\
\hline Lenaway et al. (1998) & Colorado (1989-1990) & Collaborative \\
\hline MacDorman \& Singh (1998) & United States (1991) & All types combined \\
\hline Robinson et al. (2000) & Massachusetts (1994-1995) & Restrictive \\
\hline Rosenblatt et al. (1997) & Washington (1988-1989) & Independent \\
\hline Sze et al. (2008) & West Virginia (2000-2004) & Collaborative \\
\hline
\end{tabular}

*SOP classification refers to practice authority. The restrictive classification means CNMs must be supervised or directed by a physician. Collaborative SOP requires an agreement with a physician in order to provide patient care. Independent states have no requirements for physician oversight. 
Table 2: Means by Birth Attendant, First Births, 1994-2013

\begin{tabular}{|c|c|c|c|}
\hline & $\begin{array}{l}\text { Birth Attended } \\
\text { by Physician or } \\
\text { CNM }\end{array}$ & $\begin{array}{l}\text { Birth Attended } \\
\text { by Physician }\end{array}$ & $\begin{array}{l}\text { Birth Attended } \\
\text { by CNM }\end{array}$ \\
\hline \multicolumn{4}{|l|}{ Individual Characteristics } \\
\hline Maternal age & 24.83 & 24.92 & 23.68 \\
\hline Married & 0.56 & 0.56 & 0.49 \\
\hline Female baby & 0.49 & 0.49 & 0.50 \\
\hline White & 0.78 & 0.78 & 0.78 \\
\hline Black & 0.15 & 0.15 & 0.15 \\
\hline Native American & 0.01 & 0.01 & 0.02 \\
\hline Asian & 0.06 & 0.06 & 0.05 \\
\hline Hispanic & 0.20 & 0.20 & 0.24 \\
\hline Hispanic unknown & 0.01 & 0.01 & 0.01 \\
\hline Less than high school & 0.19 & 0.19 & 0.24 \\
\hline High school & 0.27 & 0.27 & 0.28 \\
\hline Some college & 0.22 & 0.22 & 0.20 \\
\hline College & 0.26 & 0.27 & 0.21 \\
\hline Education unknown & 0.06 & 0.06 & 0.06 \\
\hline \multicolumn{4}{|l|}{ County Characteristics } \\
\hline County pop $>1,000,000$ & 0.27 & 0.28 & 0.24 \\
\hline County pop $500,000-1,000,000$ & 0.20 & 0.20 & 0.20 \\
\hline County pop $250,000-500,000$ & 0.15 & 0.15 & 0.16 \\
\hline County pop $100,000-250,000$ & 0.16 & 0.16 & 0.19 \\
\hline County pop $<100,000$ & 0.22 & 0.22 & 0.21 \\
\hline Unemployment & 6.19 & 6.17 & 6.37 \\
\hline Real income per capita (in $\$ 1000$ s) & 15.87 & 15.84 & 16.23 \\
\hline Percent poverty & 13.87 & 13.86 & 13.95 \\
\hline Primary care physicians per cap. & 1.96 & 1.96 & 1.94 \\
\hline Ever medically underserved county & 0.18 & 0.18 & 0.16 \\
\hline \multicolumn{4}{|l|}{ Maternal Health Behaviors } \\
\hline 1 st trimester prenatal care & 0.81 & 0.81 & 0.77 \\
\hline Smoked during pregnancy & 0.10 & 0.10 & 0.10 \\
\hline Drank alcohol during pregnancy (1994-2006) & 0.01 & 0.01 & 0.01 \\
\hline Adequate weight gain & 0.37 & 0.37 & 0.37 \\
\hline \multicolumn{4}{|l|}{ Labor and Delivery Outcomes } \\
\hline Induced & 0.22 & 0.22 & 0.18 \\
\hline Apparent elective induction & 0.20 & 0.21 & 0.16 \\
\hline C-section & 0.25 & 0.27 & 0.01 \\
\hline Apparent elective C-section & 0.16 & 0.17 & -- \\
\hline \multicolumn{4}{|l|}{ Birth Outcomes } \\
\hline Birth weight in grams & 3286 & 3283 & 3317 \\
\hline Birth weight $<2500$ grams & 0.06 & 0.07 & 0.04 \\
\hline Gestational weeks & 39.01 & 38.99 & 39.32 \\
\hline Gestation $<39$ weeks & 0.31 & 0.31 & 0.27 \\
\hline Birth injury & 0.002 & 0.002 & 0.002 \\
\hline
\end{tabular}

Notes: $\mathrm{N}=6,907,461$ for both attendants and $\mathrm{N}=6,383,331$ for physician attendant; $25 \%$ state-based random sample of all singleton first births born to women with no pregnancy risk factors. N=2,097,298 for CNM attendant; universe of all singleton first births born to women with no pregnancy risk factors. 
Table 3: Means of Maternal and Infant Outcomes, by Scope of Practice Legislative Environment, 1994-2013

\begin{tabular}{lcccc}
\hline & $\begin{array}{c}\text { No } \\
\text { Barriers }\end{array}$ & $\begin{array}{c}\text { Low } \\
\text { Barriers }\end{array}$ & $\begin{array}{c}\text { Moderate } \\
\text { Barriers }\end{array}$ & $\begin{array}{c}\text { High } \\
\text { Barriers }\end{array}$ \\
\hline Maternal Health Behaviors & & & & \\
1 st trimester prenatal care & 0.79 & 0.81 & 0.80 & 0.84 \\
Smoked during pregnancy & 0.09 & 0.10 & 0.10 & 0.11 \\
$\quad \begin{array}{l}\text { Drank alcohol during pregnancy } \\
\text { Adequate weight gain }\end{array}$ & 0.01 & 0.01 & 0.01 & 0.01 \\
Labor and Delivery Outcomes & 0.38 & 0.37 & 0.36 & 0.38 \\
$\quad$ Induced & 0.22 & 0.25 & 0.23 & 0.18 \\
Apparent elective induction & 0.20 & 0.24 & 0.22 & 0.16 \\
C-section & 0.24 & 0.26 & 0.27 & 0.24 \\
$\quad$ Apparent elective C-section & 0.15 & 0.15 & 0.17 & 0.16 \\
Birth Outcomes & & & & \\
Birth weight & 3305 & 3290 & 3271 & 3297 \\
Birth weight $<2500$ grams & 0.06 & 0.06 & 0.07 & 0.06 \\
$\quad$ Gestation weeks & 39.12 & 39.02 & 38.94 & 39.07 \\
Gestation<39 weeks & 0.29 & 0.31 & 0.32 & 0.31 \\
$\quad$ Birth injury & 0.003 & 0.003 & 0.002 & 0.002 \\
\hline Percent of first births & 0.18 & 0.11 & 0.46 & 0.25 \\
\hline Percent of first births attended by CNM & 0.10 & 0.06 & 0.06 & 0.09 \\
\hline Notes: The sample used is a 25\% state-based random sample of all singleton first births born to women with no \\
pregnancy risk factors.
\end{tabular}


Table 4a: Effects of SOP Laws on Maternal Health Behaviors,

Delivery Attended by Physician or Certified Nurse Midwife

\begin{tabular}{|c|c|c|c|c|}
\hline & $\begin{array}{c}\text { (1) } \\
\text { Early Prenatal } \\
\text { Care }\end{array}$ & $\begin{array}{c}(2) \\
\text { Smoked } \\
\text { during } \\
\text { pregnancy }\end{array}$ & $\begin{array}{c}\text { (3) } \\
\text { Drank during } \\
\text { pregnancy }\end{array}$ & $\begin{array}{c}\text { (4) } \\
\text { Adequate } \\
\text { Weight Gain }\end{array}$ \\
\hline Low SOP barriers & $\begin{array}{c}0.006 \\
(0.40)\end{array}$ & $\begin{array}{l}-0.006 \\
(-0.81)\end{array}$ & $\begin{array}{l}0.001 \\
(0.94)\end{array}$ & $\begin{array}{l}0.004 \\
(0.44)\end{array}$ \\
\hline Moderate SOP barriers & $\begin{array}{l}0.004 \\
(0.24)\end{array}$ & $\begin{array}{l}-0.001 \\
(-0.24)\end{array}$ & $\begin{array}{l}0.001 \\
(0.97)\end{array}$ & $\begin{array}{l}0.009 \\
(1.20)\end{array}$ \\
\hline High SOP barriers & $\begin{array}{l}-0.022 \\
(-1.16)\end{array}$ & $\begin{array}{l}-0.006 \\
(-1.02)\end{array}$ & $\begin{array}{l}0.001 \\
(0.80)\end{array}$ & $\begin{array}{l}0.008 \\
(0.95)\end{array}$ \\
\hline Maternal age & $\begin{array}{c}0.006 \\
(31.81)\end{array}$ & $\begin{array}{l}0.002 \\
(5.39)\end{array}$ & $\begin{array}{c}0.001 \\
(11.19)\end{array}$ & $\begin{array}{l}0.001 \\
(7.32)\end{array}$ \\
\hline Married & $\begin{array}{l}0.080 \\
(26.95)\end{array}$ & $\begin{array}{l}-0.096 \\
(-9.93)\end{array}$ & $\begin{array}{c}-0.009 \\
(-12.79)\end{array}$ & $\begin{array}{c}0.022 \\
(12.46)\end{array}$ \\
\hline Female baby & $\begin{array}{l}0.003 \\
(8.56)\end{array}$ & $\begin{array}{l}-0.001 \\
(-2.81)\end{array}$ & $\begin{array}{l}-0.0001 \\
(-0.65)\end{array}$ & $\begin{array}{c}0.007 \\
(15.35)\end{array}$ \\
\hline Black & $\begin{array}{l}-0.055 \\
(-19.77)\end{array}$ & $\begin{array}{l}-0.133 \\
(-12.84)\end{array}$ & $\begin{array}{l}-0.005 \\
(-10.17)\end{array}$ & $\begin{array}{l}-0.016 \\
(-10.18)\end{array}$ \\
\hline Native Am. & $\begin{array}{l}-0.062 \\
(-8.63)\end{array}$ & $\begin{array}{l}-0.027 \\
(-1.32)\end{array}$ & $\begin{array}{l}0.011 \\
(4.14)\end{array}$ & $\begin{array}{l}-0.017 \\
(-3.94)\end{array}$ \\
\hline Asian & $\begin{array}{c}-0.074 \\
(-17.78)\end{array}$ & $\begin{array}{c}-0.062 \\
(-10.07)\end{array}$ & $\begin{array}{l}-0.007 \\
(-7.56)\end{array}$ & $\begin{array}{c}0.035 \\
(12.64)\end{array}$ \\
\hline Hispanic & $\begin{array}{l}-0.049 \\
(-4.91)\end{array}$ & $\begin{array}{c}-0.142 \\
(-16.28)\end{array}$ & $\begin{array}{l}-0.006 \\
(-9.73)\end{array}$ & $\begin{array}{l}0.016 \\
(6.63)\end{array}$ \\
\hline Less than high school & $\begin{array}{l}-0.080 \\
(-21.12)\end{array}$ & $\begin{array}{l}0.044 \\
(7.10)\end{array}$ & $\begin{array}{l}0.002 \\
(9.00)\end{array}$ & $\begin{array}{l}-0.008 \\
(-3.59)\end{array}$ \\
\hline Some college & $\begin{array}{c}0.027 \\
(13.92)\end{array}$ & $\begin{array}{l}-0.058 \\
(-10.32)\end{array}$ & $\begin{array}{l}-0.000 \\
(-2.02)\end{array}$ & $\begin{array}{l}0.009 \\
(4.40)\end{array}$ \\
\hline College & $\begin{array}{c}0.050 \\
(13.18)\end{array}$ & $\begin{array}{c}-0.118 \\
(-13.08)\end{array}$ & $\begin{array}{l}-0.003 \\
(-7.61)\end{array}$ & $\begin{array}{c}0.060 \\
(26.07)\end{array}$ \\
\hline Unemployment & $\begin{array}{l}-0.002 \\
(-1.83)\end{array}$ & $\begin{array}{c}-0.0004 \\
(-0.55)\end{array}$ & $\begin{array}{l}-0.0001 \\
(-1.24)\end{array}$ & $\begin{array}{l}0.001 \\
(0.59)\end{array}$ \\
\hline Real income per capita & $\begin{array}{l}-0.001 \\
(-3.41)\end{array}$ & $\begin{array}{l}-0.001 \\
(-3.61)\end{array}$ & $\begin{array}{l}-0.0001 \\
(-2.18)\end{array}$ & $\begin{array}{l}0.001 \\
(3.81)\end{array}$ \\
\hline Percent poverty & $\begin{array}{l}-0.001 \\
(-1.93)\end{array}$ & $\begin{array}{l}-0.001 \\
(-2.00)\end{array}$ & $\begin{array}{l}-0.0001 \\
(-2.57)\end{array}$ & $\begin{array}{c}-0.0003 \\
(-1.04)\end{array}$ \\
\hline $\begin{array}{l}\text { Primary care physicians } \\
\text { per cap. }\end{array}$ & $\begin{array}{l}0.008 \\
(3.05)\end{array}$ & $\begin{array}{l}0.001 \\
(0.84)\end{array}$ & $\begin{array}{l}0.001 \\
(4.82)\end{array}$ & $\begin{array}{l}0.001 \\
(0.94)\end{array}$ \\
\hline $\begin{array}{l}\text { Observations } \\
R^{2}\end{array}$ & $\begin{array}{c}6430475 \\
0.097\end{array}$ & $\begin{array}{c}5618840 \\
0.120\end{array}$ & $\begin{array}{c}3562645 \\
0.006\end{array}$ & $\begin{array}{c}5949706 \\
0.012\end{array}$ \\
\hline
\end{tabular}


Table 4b: Effects of SOP Laws on Labor and Delivery, Delivery Attended by Physician or Certified Nurse Midwife

\begin{tabular}{lcccc}
\hline & $\begin{array}{c}(1) \\
\text { Induced }\end{array}$ & $\begin{array}{c}(2) \\
\text { Apparent } \\
\text { Elective } \\
\text { Induction }\end{array}$ & $\begin{array}{c}(3) \\
\text { C-section }\end{array}$ & $\begin{array}{c}(4) \\
\text { Apparent } \\
\text { Elective } \\
\text { C-section }\end{array}$ \\
\hline Low SOP barriers & 0.009 & 0.019 & 0.003 & 0.0004 \\
Moderate SOP barriers & $(0.33)$ & $(0.79)$ & $(0.74)$ & $(0.11)$ \\
& 0.029 & 0.033 & 0.011 & 0.015 \\
High SOP barriers & $(1.68)$ & $(1.97)$ & $(2.25)$ & $(4.32)$ \\
& 0.030 & 0.034 & 0.016 & 0.021 \\
Observations & $(2.21)$ & $(2.77)$ & $(2.84)$ & $(3.67)$ \\
$R^{2}$ & 6901578 & 6270033 & 6887640 & 5892746 \\
\hline
\end{tabular}

Notes: T-statistics in parentheses. SOP law categories are interpreted relative to states with no barriers. Models include all variables shown in Table 4a plus indicator variables for unknown education and unknown Hispanic ethnicity, county population categories, state fixed effects, and year-by-quarter fixed effects. The sample used is a $25 \%$ state-based random sample of all singleton first births born to women with no pregnancy risk factors.

Table 4c: Effects of SOP Laws on Infant Outcomes, Delivery Attended by Physician or Certified Nurse Midwife

\begin{tabular}{|c|c|c|c|c|c|}
\hline & $\begin{array}{c}\text { (1) } \\
\text { Birth } \\
\text { Weight }\end{array}$ & $\begin{array}{c}\quad(2) \\
\text { Birth } \\
\text { Weight } \\
<2500 \\
\text { grams }\end{array}$ & $\begin{array}{c}(3) \\
\text { Gestation } \\
\text { Weeks }\end{array}$ & $\begin{array}{c}\text { (4) } \\
\text { Gestation } \\
<39 \text { weeks }\end{array}$ & $\begin{array}{c}\text { (5) } \\
\text { Birth Injury }\end{array}$ \\
\hline Low SOP barriers & $\begin{array}{l}-6.344 \\
(-1.53)\end{array}$ & $\begin{array}{l}0.0003 \\
(0.30)\end{array}$ & $\begin{array}{l}-0.017 \\
(-0.72)\end{array}$ & $\begin{array}{l}0.002 \\
(0.60)\end{array}$ & $\begin{array}{c}0.000002 \\
(0.002)\end{array}$ \\
\hline Moderate SOP barriers & $\begin{array}{c}-11.254 \\
(-2.13)\end{array}$ & $\begin{array}{c}-0.00002 \\
(-0.02)\end{array}$ & $\begin{array}{l}-0.055 \\
(-2.31)\end{array}$ & $\begin{array}{l}0.008 \\
(1.59)\end{array}$ & $\begin{array}{l}0.0001 \\
(0.13)\end{array}$ \\
\hline High SOP barriers & $\begin{array}{l}-9.124 \\
(-1.57)\end{array}$ & $\begin{array}{l}-0.0001 \\
(-0.05)\end{array}$ & $\begin{array}{l}-0.060 \\
(-2.15)\end{array}$ & $\begin{array}{l}0.012 \\
(2.19)\end{array}$ & $\begin{array}{c}-0.0003 \\
(-0.24)\end{array}$ \\
\hline $\begin{array}{l}\text { Observations } \\
R^{2}\end{array}$ & $\begin{array}{c}6903133 \\
0.048\end{array}$ & $\begin{array}{c}6903133 \\
0.012\end{array}$ & $\begin{array}{c}6907461 \\
0.019\end{array}$ & $\begin{array}{c}6907461 \\
0.012\end{array}$ & $\begin{array}{c}5909771 \\
0.003\end{array}$ \\
\hline
\end{tabular}

Notes: T-statistics in parentheses. SOP law categories are interpreted relative to states with no barriers. Models include all variables shown in Table 4a plus indicator variables for unknown education and unknown Hispanic ethnicity, county population categories, state fixed effects, and year-by-quarter fixed effects. The sample used is a $25 \%$ state-based random sample of all singleton first births born to women with no pregnancy risk factors. 
Table 5: Effects of SOP Laws on Maternal and Infant Outcomes, Delivery Attended by Certified Nurse Midwife

\begin{tabular}{|c|c|c|c|c|c|}
\hline & $\begin{array}{c}\text { Early } \\
\text { Prenatal } \\
\text { Care }\end{array}$ & $\begin{array}{c}\text { Smoked } \\
\text { during } \\
\text { pregnancy }\end{array}$ & $\begin{array}{c}\text { Drank } \\
\text { during } \\
\text { pregnancy }\end{array}$ & $\begin{array}{c}\text { Adequate } \\
\text { Weight } \\
\text { Gain }\end{array}$ & Induced \\
\hline Low SOP barriers & $\begin{array}{l}0.013 \\
(0.70)\end{array}$ & $\begin{array}{l}-0.008 \\
(-1.40)\end{array}$ & $\begin{array}{l}0.002 \\
(2.13)\end{array}$ & $\begin{array}{l}-0.006 \\
(-0.39)\end{array}$ & $\begin{array}{l}0.006 \\
(0.21)\end{array}$ \\
\hline Moderate SOP barriers & $\begin{array}{l}0.001 \\
(0.03)\end{array}$ & $\begin{array}{l}-0.002 \\
(-0.43)\end{array}$ & $\begin{array}{l}0.001 \\
(0.45)\end{array}$ & $\begin{array}{l}-0.011 \\
(-0.89)\end{array}$ & $\begin{array}{l}0.028 \\
(2.04)\end{array}$ \\
\hline High SOP barriers & $\begin{array}{l}-0.017 \\
(-0.84)\end{array}$ & $\begin{array}{l}-0.012 \\
(-1.93)\end{array}$ & $\begin{array}{l}0.0004 \\
(0.23)\end{array}$ & $\begin{array}{l}-0.003 \\
(-0.29)\end{array}$ & $\begin{array}{l}0.021 \\
(1.77)\end{array}$ \\
\hline $\begin{array}{l}\text { Observations } \\
R^{2}\end{array}$ & $\begin{array}{c}1955485 \\
0.083 \\
\end{array}$ & $\begin{array}{c}1669847 \\
0.121 \\
\end{array}$ & $\begin{array}{c}1017598 \\
0.008 \\
\end{array}$ & $\begin{array}{c}1794661 \\
0.010 \\
\end{array}$ & $\begin{array}{c}2095554 \\
0.025 \\
\end{array}$ \\
\hline & $\begin{array}{c}\text { Birth } \\
\text { Weight }\end{array}$ & $\begin{array}{c}\text { Low/Very } \\
\text { Low Birth } \\
\text { Weight }\end{array}$ & $\begin{array}{c}\text { Gestation } \\
\text { Weeks }\end{array}$ & $\begin{array}{c}\text { Gestation } \\
<39 \text { weeks }\end{array}$ & Birth Injury \\
\hline Low SOP barriers & $\begin{array}{l}-8.371 \\
(-2.56)\end{array}$ & $\begin{array}{c}0.00003 \\
(0.01)\end{array}$ & $\begin{array}{l}-0.072 \\
(-3.07)\end{array}$ & $\begin{array}{l}0.008 \\
(2.51)\end{array}$ & $\begin{array}{c}-0.0002 \\
(-0.13)\end{array}$ \\
\hline Moderate SOP barriers & $\begin{array}{c}-11.879 \\
(-3.98)\end{array}$ & $\begin{array}{l}0.002 \\
(1.26)\end{array}$ & $\begin{array}{l}-0.067 \\
(-2.84)\end{array}$ & $\begin{array}{l}0.005 \\
(1.29)\end{array}$ & $\begin{array}{c}0.00003 \\
(0.03)\end{array}$ \\
\hline High SOP barriers & $\begin{array}{l}-5.638 \\
(-1.41) \\
\end{array}$ & $\begin{array}{l}0.001 \\
(0.60)\end{array}$ & $\begin{array}{l}-0.061 \\
(-2.41) \\
\end{array}$ & $\begin{array}{l}0.008 \\
(1.81)\end{array}$ & $\begin{array}{l}-0.001 \\
(-0.87) \\
\end{array}$ \\
\hline $\begin{array}{l}\text { Observations } \\
R^{2}\end{array}$ & $\begin{array}{c}2096267 \\
0.058\end{array}$ & $\begin{array}{c}2096267 \\
0.009\end{array}$ & $\begin{array}{c}2097298 \\
0.019\end{array}$ & $\begin{array}{c}2097298 \\
0.013\end{array}$ & $\begin{array}{c}1838320 \\
0.004\end{array}$ \\
\hline
\end{tabular}

Notes: t-statistics in parentheses. SOP law categories are interpreted relative to states with no barriers. Models include all variables shown in Table 4a plus indicator variables for unknown education and unknown Hispanic ethnicity, county population categories, state fixed effects, and year-by-quarter fixed effects. The sample used is the universe of all singleton first births born to women with no pregnancy risk factors reporting a CNM attendant. 


\section{Table 6a: Effects of SOP Laws on Maternal Health Behaviors, Delivery attended by Physician or Certified Nurse Midwife, Medically Underserved Counties}

\begin{tabular}{|c|c|c|c|c|}
\hline & $\begin{array}{l}\text { (1) } \\
\text { Early Prenatal } \\
\text { Care }\end{array}$ & $\begin{array}{c}(2) \\
\text { Smoked } \\
\text { during } \\
\text { pregnancy }\end{array}$ & $\begin{array}{c}\text { (3) } \\
\text { Drank during } \\
\text { pregnancy }\end{array}$ & $\begin{array}{c}\text { (4) } \\
\text { Adequate } \\
\text { Weight Gain }\end{array}$ \\
\hline Low SOP barriers & $\begin{array}{l}0.007 \\
(0.40)\end{array}$ & $\begin{array}{l}0.005 \\
(0.56)\end{array}$ & $\begin{array}{l}0.002 \\
(0.74)\end{array}$ & $\begin{array}{l}-0.013 \\
(-0.80)\end{array}$ \\
\hline Moderate SOP barriers & $\begin{array}{l}0.025 \\
(1.90)\end{array}$ & $\begin{array}{l}-0.004 \\
(-0.38)\end{array}$ & $\begin{array}{l}0.002 \\
(0.94)\end{array}$ & $\begin{array}{l}-0.003 \\
(-0.24)\end{array}$ \\
\hline High SOP barriers & $\begin{array}{l}0.020 \\
(1.33)\end{array}$ & $\begin{array}{l}-0.015 \\
(-1.49)\end{array}$ & $\begin{array}{l}0.001 \\
(0.57)\end{array}$ & $\begin{array}{l}0.001 \\
(0.07)\end{array}$ \\
\hline Maternal age & $\begin{array}{c}0.005 \\
(22.56)\end{array}$ & $\begin{array}{l}0.004 \\
(7.95)\end{array}$ & $\begin{array}{c}0.001 \\
(14.77)\end{array}$ & $\begin{array}{l}0.001 \\
(3.16)\end{array}$ \\
\hline Married & $\begin{array}{c}0.090 \\
(36.00)\end{array}$ & $\begin{array}{c}-0.112 \\
(-10.93)\end{array}$ & $\begin{array}{l}-0.010 \\
(-12.33)\end{array}$ & $\begin{array}{l}0.017 \\
(8.89)\end{array}$ \\
\hline Female baby & $\begin{array}{l}0.003 \\
(4.71)\end{array}$ & $\begin{array}{l}-0.001 \\
(-2.01)\end{array}$ & $\begin{array}{c}-0.0001 \\
(-0.72)\end{array}$ & $\begin{array}{l}0.006 \\
(7.11)\end{array}$ \\
\hline Black & $\begin{array}{c}-0.062 \\
(-14.77)\end{array}$ & $\begin{array}{c}-0.195 \\
(-21.45)\end{array}$ & $\begin{array}{l}-0.004 \\
(-8.78)\end{array}$ & $\begin{array}{l}-0.011 \\
(-3.69)\end{array}$ \\
\hline Native Am. & $\begin{array}{l}-0.069 \\
(-7.04)\end{array}$ & $\begin{array}{l}-0.057 \\
(-2.42)\end{array}$ & $\begin{array}{l}0.012 \\
(3.79)\end{array}$ & $\begin{array}{l}-0.027 \\
(-7.00)\end{array}$ \\
\hline Asian & $\begin{array}{c}-0.097 \\
(-16.59)\end{array}$ & $\begin{array}{c}-0.094 \\
(-21.72)\end{array}$ & $\begin{array}{l}-0.004 \\
(-4.64)\end{array}$ & $\begin{array}{l}0.033 \\
(6.48)\end{array}$ \\
\hline Hispanic & $\begin{array}{l}-0.102 \\
(-9.51)\end{array}$ & $\begin{array}{c}-0.189 \\
(-21.46)\end{array}$ & $\begin{array}{c}-0.005 \\
(-12.31)\end{array}$ & $\begin{array}{l}0.017 \\
(4.88)\end{array}$ \\
\hline Less than high school & $\begin{array}{c}-0.076 \\
(-19.09)\end{array}$ & $\begin{array}{l}0.073 \\
(8.96)\end{array}$ & $\begin{array}{c}0.003 \\
(10.65)\end{array}$ & $\begin{array}{l}-0.011 \\
(-6.45)\end{array}$ \\
\hline Some college & $\begin{array}{l}0.022 \\
(6.89)\end{array}$ & $\begin{array}{c}-0.083 \\
(-11.81)\end{array}$ & $\begin{array}{l}-0.001 \\
(-1.98)\end{array}$ & $\begin{array}{l}0.017 \\
(9.36)\end{array}$ \\
\hline College & $\begin{array}{l}0.038 \\
(7.12)\end{array}$ & $\begin{array}{c}-0.162 \\
(-17.75)\end{array}$ & $\begin{array}{l}-0.003 \\
(-7.04)\end{array}$ & $\begin{array}{c}0.066 \\
(24.22)\end{array}$ \\
\hline Unemployment & $\begin{array}{l}-0.002 \\
(-1.71)\end{array}$ & $\begin{array}{l}0.0002 \\
(0.30)\end{array}$ & $\begin{array}{r}-0.0003 \\
(-3.97)\end{array}$ & $\begin{array}{l}0.003 \\
(1.18)\end{array}$ \\
\hline Real income per capita & $\begin{array}{l}-0.001 \\
(-0.87) \\
\end{array}$ & $\begin{array}{l}0.001 \\
(2.21)\end{array}$ & $\begin{array}{l}0.0001 \\
(0.99) \\
\end{array}$ & $\begin{array}{l}0.001 \\
(2.02)\end{array}$ \\
\hline $\begin{array}{l}\text { Observations } \\
R^{2}\end{array}$ & $\begin{array}{c}1169255 \\
0.096\end{array}$ & $\begin{array}{c}1108153 \\
0.123\end{array}$ & $\begin{array}{c}956815 \\
0.007\end{array}$ & $\begin{array}{c}1155700 \\
0.010\end{array}$ \\
\hline
\end{tabular}


Table 6b: Effects of SOP Laws on Labor and Delivery, Delivery attended by Physician or Certified Nurse Midwife, Medically Underserved Counties

\begin{tabular}{lcccc}
\hline & $(1)$ & $(2)$ & $(3)$ & $(4)$ \\
& & $\begin{array}{c}\text { Apparent } \\
\text { Elective } \\
\text { Induction }\end{array}$ & & $\begin{array}{c}\text { C-section } \\
\text { Apparent } \\
\text { Elective } \\
\text { C-section }\end{array}$ \\
\hline Low SOP barriers & 0.023 & 0.025 & -0.004 & -0.003 \\
Moderate SOP barriers & $(0.87)$ & $(1.09)$ & $(-0.45)$ & $(-0.61)$ \\
High SOP barriers & 0.049 & 0.049 & -0.002 & -0.003 \\
& $(2.93)$ & $(2.93)$ & $(-0.16)$ & $(-0.50)$ \\
\hline Observations & 0.025 & 0.025 & -0.002 & 0.002 \\
$R^{2}$ & $(1.80)$ & $(1.73)$ & $(-0.19)$ & $(0.42)$ \\
\hline
\end{tabular}

Notes: t-statistics in parentheses. SOP law categories are interpreted relative to states with no barriers. Models include all variables shown in Table 6a plus indicator variables for unknown education and unknown Hispanic ethnicity, county population categories, state fixed effects, and year-by-quarter fixed effects. The sample used is a $25 \%$ state-based random sample of all singleton first births born to women with no pregnancy risk factors.

Table 6c: Effects of SOP Laws on Infant Outcomes, Delivery Attended by Physician or Certified Nurse Midwife, Medically Underserved Counties

\begin{tabular}{lccccc}
\hline & $\begin{array}{c}(1) \\
\text { Birth } \\
\text { Weight }\end{array}$ & $\begin{array}{c}(2) \\
\text { Low/Very } \\
\text { Low Birth } \\
\text { Weight }\end{array}$ & $\begin{array}{c}(3) \\
\text { Gestation } \\
\text { Weeks }\end{array}$ & $\begin{array}{c}(4) \\
\text { Gestation } \\
<39 \text { weeks }\end{array}$ & $\begin{array}{c}\text { Birth Injury } \\
\text { Low SOP barriers }\end{array}$ \\
Moderate SOP barriers & -14.729 & 0.001 & -0.096 & 0.009 & -0.0003 \\
High SOP barriers & $(-1.21)$ & $(0.20)$ & $(-1.91)$ & $(0.96)$ & $(-0.31)$ \\
& -10.918 & -0.001 & -0.056 & 0.005 & 0.001 \\
Observations & $(-0.79)$ & $(-0.48)$ & $(-0.94)$ & $(0.38)$ & $(0.61)$ \\
$R^{2}$ & -6.950 & -0.001 & -0.025 & 0.001 & 0.0004 \\
\hline
\end{tabular}

Notes: t-statistics in parentheses. SOP law categories are interpreted relative to states with no barriers. Models include all variables shown in Table 6a plus indicator variables for unknown education and unknown Hispanic ethnicity, county population categories, state fixed effects, and year-by-quarter fixed effects. The sample used is a $25 \%$ state-based random sample of all singleton first births born to women with no pregnancy risk factors. 
Table 7: Effects of SOP Laws on Maternal and Infant Outcomes, Delivery Attended by Certified Nurse Midwife, Medically Underserved Counties

\begin{tabular}{lccccc}
\hline & $\begin{array}{c}\text { Early } \\
\text { Prenatal } \\
\text { Care }\end{array}$ & $\begin{array}{c}\text { Smoked } \\
\text { during } \\
\text { pregnancy }\end{array}$ & $\begin{array}{c}\text { Drank } \\
\text { during } \\
\text { pregnancy }\end{array}$ & $\begin{array}{c}\text { Adequate } \\
\text { Weight } \\
\text { Gain }\end{array}$ & Induced \\
\hline Low SOP barriers & 0.011 & -0.010 & 0.003 & -0.065 & 0.021 \\
& $(0.63)$ & $(-1.57)$ & $(1.32)$ & $(-1.64)$ & $(0.66)$ \\
Moderate SOP barriers & 0.005 & 0.0002 & 0.0003 & -0.043 & 0.059 \\
& $(0.25)$ & $(0.03)$ & $(0.13)$ & $(-1.82)$ & $(3.31)$ \\
High SOP barriers & 0.017 & -0.015 & -0.001 & -0.023 & 0.040 \\
& $(0.60)$ & $(-1.54)$ & $(-0.29)$ & $(-1.24)$ & $(1.86)$ \\
\hline Observations & 324236 & 297502 & 255869 & 320313 & 339329 \\
$R^{2}$ & 0.094 & 0.125 & 0.010 & 0.017 & 0.035 \\
\hline & & & & & \\
\hline & Birth & Low/Very & Gestation & Gestation & Birth Injury \\
& Weight & Low Birth & Weeks & $<39$ weeks & \\
\hline Low SOP barriers & -19.186 & -0.001 & -0.189 & 0.030 & 0.001 \\
& $(-2.35)$ & $(-0.25)$ & $(-4.16)$ & $(4.36)$ & $(0.39)$ \\
Moderate SOP barriers & -3.899 & 0.0004 & -0.101 & 0.014 & -0.002 \\
& $(-0.46)$ & $(0.15)$ & $(-2.34)$ & $(1.58)$ & $(-1.24)$ \\
High SOP barriers & 11.751 & -0.004 & -0.054 & 0.004 & -0.002 \\
& $(1.35)$ & $(-1.28)$ & $(-1.47)$ & $(0.50)$ & $(-1.12)$ \\
\hline Observations & 339368 & 339368 & 339538 & 339538 & 309462 \\
$R^{2}$ & 0.060 & 0.011 & 0.023 & 0.015 & 0.015 \\
\hline
\end{tabular}

Notes: T-statistics in parentheses. SOP law categories are interpreted relative to states with no barriers. Models include all variables shown in Table 6a plus indicator variables for unknown education and unknown Hispanic ethnicity, county population categories, state fixed effects, and year-by-quarter fixed effects. The sample used is the universe of all singleton first births born to women with no pregnancy risk factors reporting a CNM attendant. 


\section{Table 8: Effects of SOP Laws on CNM Employment}

\begin{tabular}{|c|c|c|c|c|}
\hline \multirow[b]{2}{*}{ Lag on law: } & \multicolumn{2}{|c|}{ Licensed CNMs } & \multicolumn{2}{|c|}{ Employed CNMs } \\
\hline & One year lag & Three year lag & One year lag & Three year lag \\
\hline \multirow[t]{2}{*}{ Low SOP barriers } & -0.628 & 0.531 & 10.325 & 5.911 \\
\hline & $(-0.54)$ & $(0.81)$ & $(1.06)$ & $(0.93)$ \\
\hline \multirow[t]{2}{*}{ Moderate SOP barriers } & -0.994 & -0.725 & 3.731 & 0.937 \\
\hline & $(-0.78)$ & $(-1.04)$ & $(0.34)$ & $(0.11)$ \\
\hline \multirow[t]{2}{*}{ High SOP barriers } & 0.068 & 0.548 & 9.289 & 5.034 \\
\hline & $(0.04)$ & $(0.57)$ & $(0.74)$ & $(0.50)$ \\
\hline Observations & 765 & 765 & 316 & 316 \\
\hline$R^{2}$ & 0.939 & 0.934 & 0.615 & 0.604 \\
\hline
\end{tabular}

Notes: Weighted OLS models, t-statistics in parentheses. Models include state real income per capita, state unemployment rates, the state supply of primary care physicians per capita, and state and year fixed effects. Columns 1 and 2 also include an indicator for imputed values, where applicable. Licensed CNMs are for years 1999-2013 and include employed, unemployed and nurses out of the labor force. Employed CNMs are for years $1995,1996,1999,2000,2003,2004,2007$, and 2008. Both counts are per 100,000 women ages 14-44. 
Table 9: Effects of SOP Laws on Probability of Delivery by Certified Nurse Midwife vs. Physician

(1) (2) (3) (4)

Delivery by CNM Delivery by CNM

Medically

Underserved

Counties
Delivery by

CNM,

Parity $>1$
Delivery by CNM, Parity $>1$

Medically

Underserved

Counties

\begin{tabular}{|c|c|c|c|c|}
\hline Low SOP barriers & $\begin{array}{l}0.001 \\
(0.15)\end{array}$ & $\begin{array}{l}-0.011 \\
(-0.67)\end{array}$ & $\begin{array}{l}-0.007 \\
(-0.72)\end{array}$ & $\begin{array}{l}-0.015 \\
(-0.83)\end{array}$ \\
\hline Moderate SOP & -0.014 & -0.023 & -0.020 & -0.031 \\
\hline barriers & $(-1.74)$ & $(-1.40)$ & $(-2.10)$ & $(-1.61)$ \\
\hline High SOP barriers & -0.016 & -0.011 & -0.020 & -0.019 \\
\hline Maternal age & $\begin{array}{l}-0.003 \\
(-11.39)\end{array}$ & $\begin{array}{l}-0.002 \\
(-7.37)\end{array}$ & $\begin{array}{l}-0.002 \\
(-8.55)\end{array}$ & $\begin{array}{l}-0.001 \\
(-6.68)\end{array}$ \\
\hline Married & $\begin{array}{l}-0.001 \\
(-0.22)\end{array}$ & $\begin{array}{l}-0.002 \\
(-1.76)\end{array}$ & $\begin{array}{l}0.004 \\
(1.02)\end{array}$ & $\begin{array}{l}0.001 \\
(0.64)\end{array}$ \\
\hline Female baby & $\begin{array}{l}0.004 \\
(8.89)\end{array}$ & $\begin{array}{l}0.003 \\
(5.77)\end{array}$ & $\begin{array}{l}0.002 \\
(4.49)\end{array}$ & $\begin{array}{l}0.001 \\
(1.02)\end{array}$ \\
\hline Black & $\begin{array}{l}0.001 \\
(0.13)\end{array}$ & $\begin{array}{l}-0.002 \\
(-0.43)\end{array}$ & $\begin{array}{l}-0.004 \\
(-0.84)\end{array}$ & $\begin{array}{l}-0.005 \\
(-0.62)\end{array}$ \\
\hline Native Am. & $\begin{array}{l}0.081 \\
(3.21)\end{array}$ & $\begin{array}{l}0.132 \\
(4.51)\end{array}$ & $\begin{array}{l}0.086 \\
(2.97)\end{array}$ & $\begin{array}{l}0.142 \\
(4.22)\end{array}$ \\
\hline Asian & $\begin{array}{l}-0.011 \\
(-4.87)\end{array}$ & $\begin{array}{l}0.009 \\
(1.79)\end{array}$ & $\begin{array}{l}-0.010 \\
(-2.12)\end{array}$ & $\begin{array}{l}0.015 \\
(1.63)\end{array}$ \\
\hline Hispanic & $\begin{array}{l}0.007 \\
(1.33)\end{array}$ & $\begin{array}{l}0.007 \\
(1.04)\end{array}$ & $\begin{array}{l}0.006 \\
(1.03)\end{array}$ & $\begin{array}{l}0.006 \\
(0.70)\end{array}$ \\
\hline Less than high school & $\begin{array}{l}0.007 \\
(1.83)\end{array}$ & $\begin{array}{l}0.004 \\
(2.99)\end{array}$ & $\begin{array}{l}0.011 \\
(1.83)\end{array}$ & $\begin{array}{l}0.008 \\
(4.34)\end{array}$ \\
\hline Some college & $\begin{array}{l}-0.002 \\
(-1.53)\end{array}$ & $\begin{array}{l}-0.002 \\
(-1.53)\end{array}$ & $\begin{array}{c}-0.0001 \\
(-0.04)\end{array}$ & $\begin{array}{l}-0.001 \\
(-0.88)\end{array}$ \\
\hline College & $\begin{array}{l}-0.001 \\
(-0.35)\end{array}$ & $\begin{array}{c}-0.0002 \\
(-0.11)\end{array}$ & $\begin{array}{l}-0.003 \\
(-0.95)\end{array}$ & $\begin{array}{l}-0.001 \\
(-0.43)\end{array}$ \\
\hline Number of children & & & $\begin{array}{l}0.003 \\
(2.88)\end{array}$ & $\begin{array}{l}0.004 \\
(3.98)\end{array}$ \\
\hline Unemployment & $\begin{array}{c}-0.0002 \\
(-0.09)\end{array}$ & $\begin{array}{l}0.004 \\
(0.77)\end{array}$ & $\begin{array}{l}0.002 \\
(0.74)\end{array}$ & $\begin{array}{l}0.004 \\
(0.85)\end{array}$ \\
\hline $\begin{array}{l}\text { Real income per } \\
\text { capita }\end{array}$ & $\begin{array}{l}0.001 \\
(2.05)\end{array}$ & $\begin{array}{l}0.001 \\
(0.72)\end{array}$ & $\begin{array}{c}0.0004 \\
(0.79)\end{array}$ & $\begin{array}{l}0.002 \\
(1.34)\end{array}$ \\
\hline Percent poverty & $\begin{array}{l}0.001 \\
(0.83)\end{array}$ & & $\begin{array}{l}-0.001 \\
(-0.59)\end{array}$ & \\
\hline $\begin{array}{l}\text { Primary care } \\
\text { physicians per cap. }\end{array}$ & $\begin{array}{l}-0.007 \\
(-1.51) \\
\end{array}$ & & $\begin{array}{l}-0.009 \\
(-1.42) \\
\end{array}$ & \\
\hline $\begin{array}{l}\text { Observations } \\
R^{2}\end{array}$ & $\begin{array}{c}6907461 \\
0.030\end{array}$ & $\begin{array}{c}1220387 \\
0.053\end{array}$ & $\begin{array}{c}2580697 \\
0.031\end{array}$ & $\begin{array}{c}509579 \\
0.064\end{array}$ \\
\hline
\end{tabular}

Notes: T-statistics in parentheses. SOP law categories are interpreted relative to states with no barriers. Models include indicator variables for unknown education and unknown Hispanic ethnicity, county population categories, state fixed effects, and year-by-quarter fixed effects. The sample used in columns 1 and 2 is a $25 \%$ state-based random sample of all singleton first births born to women with no pregnancy risk factors. The sample used in columns 3 and 4 is a 10\% state-based random sample of all second or more children, born to women with no pregnancy risk factors, no previous Csection and no previous pre-term birth. 
Table 10: Effects of SOP Laws on Probability of Delivery in Freestanding Birth Clinic

(1)

Delivery in

FBC,

First birth
(2)

(3)

(4)

Delivery in FBC, Delivery in FBC Delivery in FBC,

First birth Parity $>1$

Medically

Underserved

Counties

Low SOP barriers

Moderate SOP barriers

High SOP barriers

Maternal age

Married

Female baby

Black

Native American

Asian

Hispanic

Less than high school

Some college

College

Number of children

-0.217
$(-1.50)$
$[-0.0032]$

[0.0001]

$-0.197$

$(-2.28)$

[-0.0018]

$-0.143$

$(-1.46)$

[-0.0014]

$-0.001$

$(-0.61)$

[-0.00001]

0.224

(3.58)

[0.0017]

0.022

(4.08)

[0.0002]

$-0.318$

$(-7.34)$

[-0.0019]

$-0.334$

$(-2.68)$

[-0.0018]

$-0.365$

$(-10.53)$

[-0.0020]

$-0.159$

(-4.26)

[-0.0011]

0.211

(2.12)

[0.0021]

0.112

(4.38)

[0.0010]

0.199

(5.78)

[0.0018]
[-0.0032]

$-0.381$

$(-4.53)$

[-0.0047]

$-0.360$

$(-2.42)$

[-0.0045]

0.010

(5.37)

[0.0001]

0.311

(3.78)

[0.0025]

0.009

$(0.75)$

[0.0001]

$-0.450$

$(-7.18)$

[-0.0024]

$-0.475$

$(-2.51)$

[-0.0024]

$-0.221$

$(-3.34)$

[-0.0015]

$-0.065$

$(-0.65)$

[-0.0005]

0.351

(2.85)

[0.0038]

0.029

(0.78)

[0.0003]

0.035

$(0.66)$

[0.0003]
Parity $>1$

Medically

Underserved

Counties

$-0.163$

(-1.55)

[-0.0047]

$-0.425$

$(-5.68)$

[-0.0097]

$-0.434$

$(-3.40)$

[-0.0098]

0.010

(6.25)

[0.0002]

0.409

(3.80)

[0.0051]

$-0.015$

$(-1.19)$

[-0.0002]

$-0.650$

$(-7.69)$

[-0.0056]

$-0.587$

$(-2.57)$

[-0.0052]

$-0.418$

$(-3.52)$

[-0.0043]

$-0.277$

(-1.74)

[-0.0039]

0.494

(2.60)

[0.0099]

[0.0067]

0.099

(3.71)

[0.0013]

0.168

(5.29)

[0.0024]

0.067

(4.16)

[0.0008]
0.064

(1.76)

[0.0010]

0.053

(1.15)

[0.0009]

0.089

(2.85)
[0.0014] 


\begin{tabular}{lcccc} 
Unemployment & 0.008 & 0.061 & 0.020 & 0.065 \\
& $(0.34)$ & $(3.02)$ & $(0.88)$ & $(5.37)$ \\
Real income per capita & {$[0.0001]$} & {$[0.0005]$} & {$[0.0003]$} & {$[0.0010]$} \\
& 0.003 & 0.016 & 0.002 & 0.019 \\
Percent poverty & $(0.87)$ & $(2.76)$ & $(0.40)$ & $(2.48)$ \\
& {$[0.0000]$} & {$[0.0001]$} & {$[0.00002]$} & $0.0003]$ \\
Primary care physicians & 0.016 & & 0.009 & $(1.49)$ \\
per cap. & $(3.24)$ & & $0.0001]$ & \\
& {$[0.0001]$} & & -0.013 & $(-0.44)$ \\
\hline Observations & 0.020 & & {$[-0.0002]$} & 450338 \\
\hline
\end{tabular}

Notes: Probit estimates. T-statistics in parentheses, marginal effects in brackets. SOP law categories are interpreted relative to states with no barriers. Models include indicator variables for unknown education and unknown Hispanic ethnicity, county population categories, state fixed effects, and year-by-quarter fixed effects. The sample used in columns 1 and 2 is a $25 \%$ state-based random sample of all singleton first births born to women with no pregnancy risk factors. The sample used in columns 3 and 4 is a $10 \%$ statebased random sample of all second or more children, born to women with no pregnancy risk factors, no previous $\mathrm{C}$-section and no previous pre-term birth. 